\title{
GRAMÁTICA GENERATIVA Y GRAMÁTICA ESTRUCTURAL EN EL ANÁLISIS SINTÁCTICO DE LAS CLÁUSULAS RELATIVAS EN ESPAÑOL
}

\section{INTRODUCCIÓN}

La gramática estructural y la gramática generativa son dos corrientes que han tenido gran impacto en los estudios lingüísticos del español. Es costumbre interpretar la gramática generativa como una teoría lingüística opuesta al estructuralismo ${ }^{1}$, aunque no falta quien la considere como un desarrollo encauzado en la tradición estructural2 ${ }^{2}$.

En este estudio, me propongo aportar nuevos elementos de juicio para poder arrojar más luz sobre el debate entre generativistas y estructuralistas. El objetivo que persigo no es demostrar la validez de una u otra teoría, sino mostrar en qué se distinguen. Esta tarea podría haberse emprendido comparando los postulados de la teoría estructural con los que definen la teoría generativa, pero aproximaciones de este tipo suelen dar resultados poco satisfactorios por dos razones. La primera es que las teorías lingüísticas no son homogéneas; la segunda, que en la investigación lingüística es grande la distancia que media entre los postulados teóricos y la práctica analítica. Esta distancia se manifiesta sobre todo en la necesidad de adoptar hipótesis auxiliares que son relativamente independientes del marco teórico en que se usan.

En vez de considerar una teoría lingüística como una serie de

1 Véanse F. D'InTrono, Sintaxis transformacional del español, Cátedra, Madrid, 1979; C.-P. OTERo, Introducción a la lingüistica transformacional, Siglo XXI, México, 1968; N. RuweT, Introduction à la grammaire générative, Plon, Paris, 1967.

2 Véase por ejemplo F. Rodríguez Adrados, Lingüistica estructural, Gredos, Madrid, 1969-1971, 2 ts. 
postulados teóricos, creo oportuno investigar la metodología implícita tal como se pone de manifiesto en estudios específicos sobre cuestiones lingüísticas. El estructuralismo no puede ser identificado con el conjunto de los enunciados sobre qué debería ser la teoría estructural, sino que comprende las investigaciones sobre cuestiones específicas cuya selección y elaboración define su marco teórico. De manera similar, la teoría generativa no se puede entender como una serie de discusiones sobre puntos teóricos ni como el conjunto de los modelos específicos que han sido propuestos $^{3}$, sino que se define como una serie de actividades desplegadas para solucionar problemas específicos. La comparación del generativismo con el estructuralismo que es tema de esta investigación se limita, por tanto, a elucidar lo que han intentado solucionar estructuralistas y generativistas al estudiar un problema determinado, a saber, el uso de los pronombres relativos en español. Se trata, pues, de verificar qué puntos problemáticos han creído descubrir generativistas y estructuralistas y en qué dirección apuntan las soluciones que proponen. Veremos que, de hecho, los estructuralistas se distinguen de los generativistas en la selección de las cuestiones que creen deber tratar; la comparación de las dos teorías consistirá en una tentativa de descubrir por qué se han escogido tópicos distintos en el estudio de datos comparables.

El uso de los pronombres relativos ha sido tema de investigación predilecto entre los generativistas ${ }^{4}$, aunque su aplicación al

3 Por esta razón no son recomendables las introducciones tales como: $\mathrm{R}$. Hadlich, A Transformational Grammar of Spanish, Prentice Hall, New Jersey, 1971; H. López Morales, Introducción a la lingüistica generativa, Alcalá, Madrid, 1974, o los capítulos que dedica a la teoría generativa F. MARcos MARín, Lingüistica y lengua española, Cincel, Madrid, 1975; la mejor introducción actual, aunque ya un poco anticuada, es la de F. D'InTROno, op. cit.

4 Véase N. Chomsky, "On WH-Movement", en P. Culicover, T. Wasow y A. Akmajian (eds.), Formal Syntax, Academic Press, New York, 1977, y las referencias bibliográficas que se hallan en él; estudios posteriores comprenden, en el ámbito de las lenguas romances, G. Cinque, "La Sintassi dei Pronomi Relativi cui e quale nell' Italiano Moderno', Rivista di Grammatica Generativa, 1978, núm. 3, 31-126; "On the Theory of Relative Clauses and Markedness"', $L R U, 2$ (1981), 247-294; P. HirSCHBüHLER, “Two Analyses of Free Relatives in French" ${ }^{5}$, Montreal Working Papers in Linguistics, 1978, núm. 6, 137-152; P. Hirschbühler y M. L. Rivero, "A Unified Analysis of Matching and Non-Matching Free Relatives in Catalan'”, en V. A. Burke y J. Pustejovsky (eds.), Proceedings of the Eleventh Meeting of the North Eastern Linguistic Society, Amherst, MA, 1981; y R. KAYNE, "French Relative que', en M. Luján y F. Hensey (eds.), Current Studies in Romance Linguistics, Georgetown University Press, Washington, 1974. 
español ha dado hasta el momento pocos resultados ${ }^{5}$. Los estructuralistas no le han dedicado tanta atención, pero disponemos de un estudio muy valioso y bastante completo ${ }^{6}$. En éste, se han tratado todos los puntos relacionados con el uso de los pronombres relativos en español que son pertinentes dentro del marco de la teoría estructuralista, descartándose al mismo tiempo los que no tienen pertinencia en ella.

En la elaboración de este estudio me he dejado guiar por mis experiencias personales. Por un lado, nunca me han convencido las consideraciones teóricas que no se basen en análisis certeros de determinados fenómenos lingüísticos. Por otro, tampoco me han convencido los análisis lingüísticos que no se basen en un modelo más general de teoría lingüística. Otro tanto se puede decir con respecto a las discusiones metodológicas. En ellas se suele dedicar poca atención a la metodología implícita de los estudios que se emprenden dentro de un marco teórico determinado, metodología que muchas veces no tiene correspondencia completa con la que se exige en la teoría "oficial'". De ahí que me haya parecido útil verificar qué recursos analíticos se han usado en la investigación de la sintaxis de las cláusulas relativas del español en las dos corrientes, antes de determinar en qué puntos metodológicos se distingue el generativismo del estructuralismo. Con esta aproximación he evitado verme obligado a comparar aspectos del análisis lingüístico que son independientes de la teoría general en que se manejan y, por ende, no pertinentes en el momento de comparar las teorías. No son los modelos específicos concernientes a una parcela limitada de los fenómenos lingüísticos los que se pueden considerar como característicos de las teorías que los han adoptado. Por el contrario, los modelos parciales pueden adoptarse en teorías distintas sin afectar para nada sus características definitorias. Se trata, pues, de descubrir la manera en que se ponen en práctica los modelos parciales que se utilizan, intentando lograr así una caracterización más completa y general de lo que constituye su meollo teórico.

La lectura de este estudio no debe emprenderse con la esperanza de hallar en él la última novedad en lo que concierne a la

${ }^{5}$ Véanse M. L. Rivero, "Las relativas restrictivas con que", NRFH, 31 (1982), 195-234; y J. Schroten, "Two Approaches to the Distribution of Spanish Relative Pronouns", Estudis Grammaticals. (Working Papers in Linguistics), Universitat Autònoma de Barcelona, Bellaterra, 1984, t. 1.

${ }^{6}$ Véase E. Alarcos LlORACH, "Español /quef', Estudios de gramática funcional del español, Gredos, Madrid, 1970, cap. 10. 
gramática generativa o a la gramática estructural; tampoco dará como fruto una solución definitiva de cómo tratar la sintaxis de las cláusulas relativas en español. El objetivo que he perseguido es a la vez más modesto y más ambicioso. Se trata de ejemplificar cómo se emprenden las investigaciones dentro de los dos marcos teóricos, cómo se seleccionan los problemas y cómo se buscan las soluciones. Los problemas y las soluciones que se discuten en una teoría sirven para obtener un enfoque más claro del alcance de las discusiones en la otra teoría. De esta manera lograremos comprender mejor en qué se distinguen los generativistas de los estructuralistas, lo que permitirá una visión más equilibrada del estado actual de la lingüística.

1. LA DISTRIBUCIÓN DE LOS PRONOMBRLSS RLIAATIVOS EN ISPAÑNOL.

\subsection{Introducción}

Son cláusulas relativas las oraciones subordinadas subrayadas en los ejemplos (1)-(3):

(1) El chico que viene es vecino mío

(2) El chico que ves es vecino mío

(3) El chico de que hablo es vecino mío

El sintagma nominal el chico, que precede a las cláusulas relativas, es su antecedente; son construcciones relativas las secuencias que se componen de una cláusula relativa y su antecedente. La cláusula relativa define una propiedad o calidad que se atribuye al antecedente; éste, a su vez, cumple una función gramatical en la cláusula relativa. Por ejemplo, el antecedente el chico se interpreta como sujeto de la cláusula en (1), como complemento directo en (2) y como complemento preposicional de régimen en (3). El antecedente, aunque se entiende como función de la cláusula relativa, no es constituyente de la misma, sino que lo es de la oración principal; en las oraciones (1)-(3), es el sujeto de la oración principal. El antecedente, por tanto, se repite en la cláusula relativa mediante los "sintagmas relativos" que en (1), que en (2), de que en (3). El uso de que, en (1), es, pues, señal de que el antecedente debe entenderse como el sujeto de viene, de la misma manera que, en (2), que señala que el antecedente debe entenderse como el complemento directo de ves; en (3), la secuencia de que 
indica que el antecedente se interpreta como un complemento preposicional precedido por de en la cláusula relativa.

En este apartado investigaremos la distribución de los signos que desempeñan el mismo papel que que en (1)-(3); éstos se llaman pronombres relativos. El apartado se divide en cuatro secciones. En la primera, se estudia la distribución de los pronombres relativos y la descripción de la misma; se define un contexto especial en el que no se admiten pronombres relativos salvo que. En la segunda, se propone una manera de describir la posición e interpretación funcional de los constituyentes que contienen un pronombre relativo. La tercera sección está dedicada a fundamentar una revisión importante de la descripción de la distribución de los pronombres relativos; se trata de delimitar de una manera más exacta el contexto en que no se admiten pronombres relativos salvo que. Se discuten al respecto las llamadas cláusulas relativas "libres", que carecen de antecedente; éstas van a desempeñar un papel fundamental en el tratamiento de la sintaxis de los pronombres relativos. En la cuarta sección se introduce el concepto de "transposición categorial" que constituye la base del análisis estructural de las cláusulas relativas. Las conclusiones se hallan al final de este apartado.

\subsection{Los pronombres relativos: su distribución}

Los ejemplos (1)-(3) se interpretan de manera similar a (4)-(6):

(4) El chico - él viene - es vecino mío

(5) El chico - lo veo - es vecino mío

(6) El chico - de él hablo - es vecino mío

El parecido consiste en que, en las cláusulas parentéticas subrayadas, también hay un morfema que refiere al antecedente $e l$ chico, indicando al mismo tiempo su función gramatical en la cláusula parentética. Es obvio que el parecido no se extiende a la interpretación total, puesto que (1) y (4), (2) y (5), (3) y (6) no son oraciones sinónimas. Los morfemas que tienen valor referencial a un antecedente se dicen anafóricos. Los morfemas con valor anafórico en (4)-(6) son pronombres personales que tienen la categoría léxica $\mathrm{N}$; él y lo son nombres anafóricos, o sea, que tienen la capacidad de referir a otro nombre o sintagma nominal o de "repetir' la referencia del SN con que se dicen anafóricos.

En vista del paralelismo que acabamos de observar respecto 
a (1)-(3) y (4)-(6), suponemos que el signo que, en (1)-(3), es también un nombre sustantivo con valor anafórico ${ }^{7}$.

La estructura sintagmática de (1)-(3) se halla representada en (7)-(9), respectivamente:

(7) [sN el chico [o' [COMP [SN que $]][\mathrm{sv}$ viene $]]]-[\mathrm{sv}$ es [sN vecino mío]]

(8) $[\mathrm{sN}]$ el chico $\left[\mathrm{O}^{\prime \prime}[\mathrm{COMP}[\mathrm{SN}\right.$ que $]][\mathrm{sv}$ veo $\left.\left.]\right]\right]-[\mathrm{sv}$ es $[\mathrm{sv}$ vecino mío]]

(9) $[\mathrm{sN}$ el chico [o' [COMP [sP de [sN que $]]][\mathrm{sv}$ hablo $]]]-[\mathrm{sv}$ es [SN vecino mío]]

De acuerdo con esta descripción, que es pronombre relativo, es decir, un pronombres como él, lo, que se usa en construcciones relativas, distinguiéndose de los pronombres personales como él, lo en que se halla al principio de la oración subordinada $\mathrm{O}^{\prime}$, en la posición denominada COMP. No es que el único pronombre relativo que se puede usar; por ejemplo, en (3) puede usarse en vez de que el pronombre relativo quien o el pronombre relativo compuesto por el artículo definido el y que o cual:

(10)a. El chico de quien hablo es vecino mío

b. El chico del que hablo es vecino mío

c. El chico del cual hablo es vecino mío

Es sorprendente que la sustitución de que en (1) por los pronombres relativos quien, el que, el cual sea imposible, ya que no son aceptables (1l)a.-c.:

(11)a. ${ }^{*}$ E1 chico quien viene es vecino mío

b. ${ }^{*}$ El chico el que viene es vecino mío

c. ${ }^{*}$ El chico el cual viene es vecino mío

Tampoco es posible la sustitución en (2), puesto que (12)a.-c. son inadmisibles:

(12)a. *El chico quien ves es vecino mío

b. ${ }^{*}$ El chico el que ves es vecino mío

c. ${ }^{*}$ El chico el cual ves es vecino mío

${ }^{7}$ Los pronombres personales átonos pueden referir a "objetos" no mencionados antes en el discurso, mientras que los pronombres relativos requieren antecedentes en el discurso. Se podría sostener, pues, que los pronombres personales coinciden con el antecedente en designar al mismo referente, o sea, que el referente que obtiene el antecedente y el que obtiene el pronombre personal pueden llegar a coincidir "accidentalmente". Los pronombres relativos, en cambio, sólo obtienen valor referencial vía el antecedente, coincidiendo "esencialmente" con él; a este respecto véase G. Evans, "Pronouns", LI, 11 (1980), 337-363. 
Es obvio que (12) se puede "salvar" si introducimos la preposición $a$, cuyo uso es obligatorio ante los complementos directos humanos y definidos; cf. (13):

(13)a. El chico a quien ves es vecino mío

b. El chico al que vez es vecino mío

c. El chico al cual ves es vecino mío

Tomando en consideración datos parecidos del francés, Richard Kayne ${ }^{8}$ ha observado que es la presencia de la preposición la que hace posible el uso de los pronombres relativos quien, el que, el cual. Si éstos no van "protegidos" por una preposición, hallándose "indefensos", no se pueden usar, como es el caso en (11) y (12).

Por lo visto, que es excepcional en que no necesita ser protegido. En otras palabras, la posición indefensa, o sea, la inicial de cláusula relativa no precedida de preposición, es incompatible con el uso de los pronombres relativos quien, el que, el cual, aunque es compatible con que. Esta limitación se puede formular diciendo que no se admiten pronombres relativos en posición indefensa. Si representamos la clase de los pronombres relativos mediante la fórmula $\mathrm{REL}=\{$ que, quien, el que, el cual $\}$, la restricción se puede formalizar de la manera que mostramos en (14):

$(14) *\left[\mathrm{O}^{\prime}[\right.$ COMP $[\mathrm{SN}$ REL $\left.]] \ldots\right] \ldots$, si REL $\neq$ que

Se explica el carácter excepcional de que, si lo consideramos no como pronombre relativo, sino como la conjunción que que se halla también en casos tales como (15):

(15) El chico dice que viene Juan

En (15), que no representa al antecedente el chico, sino que sólo sirve para señalar que la cláusula de que forma parte está subordinada al verbo principal. Si el que "relativo" en (1) y (2) se interpreta como mera conjunción, el valor anafórico que parecía tener debe ser consecuencia de otras propiedades de la cláusula relativa y no puede deducirse de ninguna propiedad inherente de que.

En resumidas cuentas, la hipótesis inspirada en Kayne lleva a suponer: (i) que son pronombres relativos que, quien, el que, el cual precedidos por preposición; (ii) que los pronombres relativos no se admiten en posición indefensa; (iii) que el que "relativo"

${ }^{8}$ R. KAYNE, art. cit. 
en posición indefensa no es pronombre relativo, sino una mera conjunción, de modo que el antecedente no se repite en la cláusula relativa mediante que, sino a consecuencia de otras propiedades de la cláusula relativa que conviene determinar.

\subsection{Los pronombres relativos: su posición $e$ interpretación funcional}

Los pronombres relativos y las conjunciones se hallan al comienzo de la cláusula a la que pertenecen, a diferencia de los pronombres no relativos. Comparemos al respecto los ejemplos (3) y (6):

(3) El chico de que hablo es vecino mío

(6) El chico - de él hablo - es vecino mío

Mientras que el sintagma de él, en (6), puede hallarse también en posición postverbal, esto no es posible con el sintagma relativo de que, en (3):

$$
\begin{aligned}
& \left(3^{\prime}\right){ }^{*} \text { E1 chico hablo de que es vecino mío } \\
& \left(6^{\prime}\right) \text { El chico - hablo de él - es vecino mío }
\end{aligned}
$$

Recuérdese que los sintagmas relativos pueden referir a cualquier función gramatical. Es curioso notar que a los pronombres relativos les corresponde siempre la posición inicial de la cláusula, a pesar de su capacidad de representar distintas funciones gramaticales asociadas con distintas posiciones.

Para poder describir adecuadamente esta característica de las cláusulas relativas, supongamos que se halla un constituyente de forma "cero", o sea, un constituyente vacío, en la posición que le corresponde a la función a la que refiere el pronombre relativo (o la conjunción que "relativo"); además, supongamos que el pronombre relativo y la conjunción que forman parte de $\mathrm{O}^{\prime}$, y que se hallan en COMP, quedando, pues, al margen de $\mathrm{O}^{\prime 9}$.

De acuerdo con estos supuestos, la representación sintáctica de (1)-(3) se halla en (16)-(18), en los cuales $e$ es símbolo de falta de expresión fonológica:

mío

(16) El chico $\left[\mathrm{O}^{\prime}\right.$ [COMP que] [o $[\mathrm{SN} \ell]$ viene $\left.]\right]$ es vecino

${ }^{9}$ Véanse N. ChOмsкy, art. cit.; Lectures on Government and Binding, Foris, Dordrecht, 1981; Some Concepts and Consequences of the Theory of Government and Binding, MIT Press, Cambridge, 1982. 
(17) El chico [o' [COMP que] [o ves [sN $\ell]]]$ es vecino mío

(18) El chico [o' [COMP de que] [o hablo [SP $e$ ]]] es vecino mío

A partir de estas representaciones sintagmáticas de (1)-(3) podemos obtener las interpretaciones correspondientes, derivando de ellas las estructuras "lógicas" pertinentes ${ }^{10}$. La derivación se efectúa aplicando las dos reglas que formulamos en (19) y (20):

(19) Sustituir REL por una copia del antecedente.

(20) Mover el sintagma inicial de la cláusula a la posición que ocupa el sintagma vacío, o sea, sustituir $\ell$ por el sintagma inicial de la cláusula.

Por ejemplo, la derivación de (18) se muestra en (21):

(21)a. El chico [o, [COMP [sP de que]] [o hablo [sp $e$ ]]] es vecino mío

Sustitución de que por una copia del antecedente

b. El chico [o' [COMP [sP de el chico]] [o hablo [sP $e]]]$ es vecino mío

Sustitución de $e$ por el sintagma inicial

c. El chico [o' [o hablo [sP de el chico]]] es vecino mío

La interpretación de la cláusula relativa se establece sobre la base de (21)c; es obvio que la función gramatical y el contenido léxico se han reconstruido debidamente.

Suponiendo por el momento que este análisis es adecuado, consideremos de nuevo el problema de que en posición indefensa. De acuerdo con el análisis que presentábamos en la sección anterior, que no puede ser pronombre relativo, sino que debe identificarse como conjunción. La regla (19), por tanto, no sirve para reconstruir la función gramatical del sujeto que debemos obtener en (16) o la del complemento directo que debemos obtener en (17). El paralelismo entre (16), (17) y (18) puede ser restablecido adoptando la hipótesis de que al lado de la conjunción que se halla un pronombre relativo cero. Según esta hipótesis, (22) y (23) serían las estructuras que corresponden a (16) y (17):

${ }^{10}$ La estructura llamada "lógica" es la que se obtiene al aplicar ciertas operaciones "lógicas" a la estructura sintáctica; véase sobre todo R. MAY, $A$ Grammar of Quantification, tesis doctoral, Massachusetts Institute of Technology, Cambridge, 1977; N. Chомsкy, art. cit. El nivel que se define aquí, en realidad, no tiene correspondencia exacta con la estructura lógica establecida en estos estudios, pero se le parece lo suficiente para poder utilizar el término. 

es vecino mío

(22) $\mathrm{El}$ chico [O' [COMP que [ $\left.\left.\mathrm{SN}_{\mathrm{REL}} e\right]\right][\mathrm{O}[\mathrm{SN} e]$ viene]] vecino mío

(23) $\mathrm{El}$ chico $\left[\mathrm{O}^{\prime}\left[\mathrm{COMP}\right.\right.$ que $\left.\left[\mathrm{SN}_{\mathrm{RFL}} e\right]\right][\mathrm{o}$ ves $\left.[\mathrm{SN} e]]\right]$ es

En resumidas cuentas, las cláusulas relativas se analizan de dos maneras distintas.

En primer lugar, si COMP se forma con una preposición más un pronombre relativo, el pronombre debe ser interpretado mediante su sustitución por una copia del antecedente; el COMP interpretado debe ser desplazado a la posición que ocupa el sintagma vacío. En segundo lugar, si COMP se compone de que, esta conjunción va seguida de un pronombre relativo vacío, que se halla también en COMP; el pronombre vacío es sustituido por una copia del antedecente, que, a su vez, debe ser desplazado a la posición vacía en $\mathrm{O}$.

1.3. La restricción sobre la posición indefensa y el análisis de las construcciones relativas carentes de antecedente

La restricción sobre la posición indefensa a la que parece que están sujetos los pronombres relativos desempeña un papel importante en la distribución de los mismos. No obstante, no es válida en todas las circunstancias. Recuérdese que los pronombres relativos se hallan en oraciones subordinadas donde ocupan la posición de COMP, el primer constituyente de $\mathrm{O}^{\prime}$. La restricción sobre la posición indefensa puede formularse, pues, de la manera siguiente:

$$
\text { (24) }{ }^{*}\left[O^{\prime}\right. \text { [COMP [SN REL]] O] }
$$

De acuerdo con la interpretación (24), la posición inicial de la cláusula relativa es incompatible con los pronombres relativos de la categoría SN, o sea, que son inadmisibles las cláusulas relativas introducidas por SN relativo.

El ejemplo (25), sin embargo, contiene una cláusula relativa introducida por SN relativo, sin que esto produzca inaceptabilidad, lo cual muestra que la restricción no es válida en todas las circunstancias.

(25) Quien te quiere te hará llorar

El análisis más natural de (25) consiste en suponer que quien 
se halla en la posición de COMP dentro de la cláusula relativa ${ }^{11}$. Este análisis es el que mostramos en (26):

(26) [o' [COMP [SN quien]] [o [sN $e]$ te quiere]] te hará llorar

De ser cierto este análisis, debe ser abandonado la restricción que ha sido formulada en (24). En vista de la importancia que tiene esta conclusión, conviene demostrar que (25) no puede ser analizado de otra manera que la que se muestra en (26).

Observemos primero que el análisis de (25) que se muestra en (27) puede ser descartado ya desde un principio:

(27) [o [sN quien] te quiere] te hará llorar

Según (27), quien sería el sujeto sintáctico de la cláusula relativa y no se hallaría en COMP. Si esto fuese cierto, debería ser posible hallar este sujeto en posición postverbal, puesto que el sujeto sintáctico en o siempre se admite en posición postverbal. De la inaceptabilidad de (28) se deduce que esto es imposible:

(28) * [te quiere quien] te hará llorar

Otra alternativa sería asignar a (25) la estructura que se muestra en (29):

(29) [SN quien] [o te quiere] [sv te hará llorar]

El análisis (29) tiene dos desventajas serias. En primer lugar, se interpreta quien como el antecedente, lo que llevaría a suponer que esta palabra también se halla como antecedente en otros tipo de construcciones relativas. Esto es, evidentemente, imposible; cf. (30):

(30) *Quien del que hablas te hará llorar

En segundo lugar, la cláusula relativa carecería de COMP, constituyente que se halla en todas las demás oraciones subordinadas, de modo que constituiría un tipo especial de cláusula relativa.

${ }^{11}$ De estas cláusulas relativas "libres" o carentes de antecedentes se habla en J. Bresnan y J. Grimshaw, "The Syntax of Free Relatives in English", LI, 9 (1978), 331-391; A. Groos y H. van Riemsdjk, "Matching Effects in Free Relatives: A Parameter of Core Grammar", en A. Belletti, L. Brandi y L. Rizzi (eds.), Theory of Markedness in Generative Grammar, Scuola Normale Superiore di Pisa, 1981; S. PlanN, Relative Clauses in Spanish Without Overt Antecedent and Related Constructions, University of California Press, Berkeley-Los Angeles, 1981; P. Hirschbühler y M. L. Rivero, art. cit., donde se hallan también otras referencias bibliográficas. 
Como estas dos desventajas se dan juntas y están relacionadas obviamente, el análisis (29) es doblemente excepcional. Se sigue que el análisis (26) es el más natural.

La nómina de los pronombres relativos no se limita a quien, sino que comprende el que, el cual y que. Las cláusulas relativas carentes de antecedente, que constituyen el tipo ejemplificado en (25), también pueden ser introducidas por el que, como en (31):

(31) El que te quiere te hará llorar

Dado el paralelismo de (25) y (31), el análisis de este ejemplo que más viene a mano es el que se muestra en (32):

(32) [o' [COMP el que] [o $e$ te quiere]] [sv te hará llorar]

El carácter complejo de el que permite otra interpretación ${ }^{12}$, ausente de las construcciones con quien, puesto que se puede interpretar como la secuencia de $e l$ antecedente y que, pronombre relativo. De acuerdo con este análisis, (31) debería tener la representación que se exhibe en (33):

(33) [sN el] [o' [COMP que] [e te quiere]] [sv te hará llorar]

De hecho, se impone este análisis en ciertos contextos, del tipo que se presenta en (34):

(34) El hombre que te odia te hará reír y el que te quiere te hará llorar

La interpretación usual de (34) es que se sobreentiende hombre en la segunda parte, o sea, que se trata de la elipsis de hombre bajo la influencia de hombre en la primera parte de la oración. No obstante, el análisis (32) se impone en los contextos en que no es posible invocar la elipsis de un nombre mencionado antes.

En las construcciones relativas carentes de antecedentes se usan, pues, quien o el que; es sorprendente observar que ni el cual ni que son admisibles en estas construcciones:

(35)a. *E1 cual te quiere te hará llorar

b. ${ }^{*}$ Que te quiere te hará llorar

El rechazo de el cual y que en este tipo de construcciones, que no tiene explicación, no impide que tanto quien como el que se admitan en posición "indefensa', o sea, sin necesidad de ser protegidos por una preposición en COMP.

${ }^{12}$ El doble análisis se presenta más detalladamente en M. L. Rivero, art. cit. 


\subsection{Resumen}

La distribución de los pronombres relativos puede describirse de una manera adecuada teniendo en cuenta la distinción que hemos trazado entre la posición protegida y la indefensa. La conclusión más sorprendente es que no se admiten los pronombres relativos en la posición indefensa. En posición protegida se hallan quien, el que, el cual ${ }^{13}$, que son los pronombres relativos del español.

Debido a la imposibilidad de parte de los pronombres relativos de hallarse en posición indefensa, la relativización de las funciones gramaticales que no se señalan con preposición (el sujeto, el complemento directo y el atributo) no se realiza mediante el uso de pronombres relativos, sino empleando la conjunción que, seguida ésta por un pronombre relativo vacío. Los detalles de este proceso deben ser estudiados más detenidamente. Por ahora, basta con saber que hay dos tipos distintos de cláusulas relativas, a saber, el que se obtiene mediante el uso de pronombres relativos precedidos de preposición y el que se obtiene mediante el uso de la conjunción que, seguida de un pronombre vacío.

La restricción sobre la posición indefensa, según la cual no se admiten los pronombres relativos en COMP si no se hallan protegidos por una preposición, parece ser incompatible con la aceptabilidad de las llamadas cláusulas relativas carentes de antecedente con el sujeto relativizado. En éstas, el pronombre relativo no precedido de preposición se halla en COMP.

\section{AnÁlisis estructuralista de las ClÁUsulas relativas}

\subsection{Introducción}

En el apartado anterior hemos concluido que las cláusulas relativas se dividen en dos tipos, el uno introducido por una prepo-

${ }^{13}$ En posición protegida también se halla que, como en el ejemplo (i):

(i) El hombre de que hablo es vecino mío

De acuerdo con el criterio de la posición protegida, que se comporta como un verdadero pronombre relativo. No se explica, sin embargo, por qué no se admite que en un complemento directo precedido de $a$, como en (ii):

(ii) ${ }^{*}$ El hombre a que veo es vecino mío

El que en posición indefensa no puede ser pronombre relativo, por la sencilla razón de que los pronombres no se admiten en esta posición. Se trata, pues, de un morfema distinto, aunque homófono. 
sición seguida de un pronombre relativo, el otro introducido por que seguido de un pronombre relativo cero.

Presentaremos en este apartado un análisis estructuralista de las cláusulas relativas ${ }^{14}$. Como el análisis se basa en presupuestos estructurales de tipo funcional, no podemos apreciar debidamente el método si no tenemos en cuenta las bases de la teoría ${ }^{15}$.

\subsection{El modelo funcional y el análisis de las cláusulas relativas}

2.1.0. La teoría del estructuralismo de tipo funcional se basa en las consideraciones que pasamos a resumir.

Las palabras se dividen en dos clases, las independientes o léxicas ${ }^{16}$ y las dependientes o gramaticales. Son independientes las palabras que pueden hallarse solas en el discurso. Por ejemplo, casas es palabra independiente en: ¿qué viste? - casas.

Otras palabras nunca se hallan solas y se utilizan solamente si van acompañadas de una palabra independiente. Por ejemplo, $e l$ y $d e$ se hallan en el sintagma $e l d e J u a n$, pero no es viable el uso de $e l$ o de o $e l$ de solamente.

Se combinan las palabras léxicas con cero, una o más palabras gramaticales formando sintagmas; por ejemplo, son sintagmas: casas, las casas, de las casas, el de las casas, con el de las casas. Cada palabra léxica es el término nuclear de un sintagma simple; en los ejemplos que acabamos de ver, casas es siempre el término nuclear.

Los sintagmas pueden ser independientes o contraer relación de dependencia o interdependencia con otro(s) sintagma(s). Por ejemplo, en el discurso hallamos: comimos pan y comimos. El sintagma comimos puede ser independiente siempre, mientras que pan permite la independencia sólo en contextos especiales, como en las respuestas. En: comimos pan, el sintagma pan depende de comi-

${ }^{14}$ Véase E. Alarcos Llorach, op. cit.

${ }^{15}$ Véanse $i d$; A. MARTinet, "Les fonctions grammaticales", LingP, 13 (1977), 3-14; B. PotTier, Gramatica del español, Alcalá, Madrid, 1970; L. TesNIÈRE, Éléments de syntaxe structurale, Klincksieck, Paris, 1959.

${ }^{16}$ Alarcos (op. cit., cap. 10,3) habla de "signos autónomos", que define así: "Entendemos por autónomo todo signo mínimo o complejo capaz de desempeñar por sí solo en la estructura de la oración una función determinada, y por tanto - en los casos de elipsis - susceptible de funcionar asociado con un determinado signo oracional ( = contorno oracional más modo oracional) como equivalente de oración". La palabra es, pues, el signo mínimo autónomo. 
mos, ya que su utilización requiere la de comimos o de otra palabra de la misma categoría léxica que comimos. Los términos nucleares de los sintagmas simples que siempre pueden tener existencia independiente forman la clase léxica de los verbos ${ }^{17}$; los que dependen de los verbos son los nombres. La tercera clase léxica que podemos distinguir es la de los adjetivos; éstos dependen de los nombres, como en: pan tierno, donde el adjetivo tierno depende del nombre pan.

Las clases léxicas se definen, pues, deductivamente, de una manera puramente formal.

Los sintagmas dependientes se llaman adyacentes; el sintagma de que dependen los adyacentes se llama el núcleo. El núcleo y sus adyacentes constituyen un sintagma complejo que tiene la misma función que la del núcleo.

Las llamadas funciones gramaticales tales como el sujeto, el implemento ( = complemento directo), el complemento ( $=$ complemento indirecto), el suplemento ( = complemento preposicional de régimen) y el atributo son valores específicos de los adyacentes nominales o adjetivos; su valor específico se indica mediante indicios funcionales, como las preposiciones, o la posición respecto al núcleo de que dependen o el uso de morfemas ligados concordados.

\subsubsection{Compárense los dos ejemplos siguientes:}

(36)a. Anunció sus propósitos

b. Anunció que vendría

En (36)a., el sintagma sus propósitos tiene función de implemento; como su núcleo es un nombre, se trata de una función nominal. En (36)b., el sintagma que vendría tiene núcleo verbal vendria, de modo que debería interpretarse como función verbal. No obstante, que vendría es un implemento y debe ser tratado como fun-

17 Por extensión, todas las palabras con propiedades formales similares a las de comimos (como son las desinencias que selecciona) constituyen la clase de las palabras independientes, aun si algunas (o muchas) de ellas exigen la presencia de un adyacente en función de complemento directo (por ejemplo, metimos sólo se admite en contextos tales como metimos el pan en el horno, excluyéndose su uso independiente: *metimos). Basta, pues, con que algunos miembros sean independientes para que la independencia pueda ser considerada como propiedad de la clase. Véase a este respecto Z. HARRIS, Methods in Structural Linguistics, University of Chicago Press, Chicago, 1951, quien caracteriza las clases de una manera parecida. 
ción nominal. Por lo visto, que transpone la función verbal a la nominal, o sea, que habilita el verbo a la función nominal que debe cumplir en (36)b. El efecto de la transposición se representa en $(37)^{18}$ :

(37) [N que [v vendría]]

La transposición se representa, pues, añadiendo corchetes de la categoría apropiada al sintagma con que se asocia el transpositor que; la operación misma se define en (38):

(38) [que v] $\rightarrow[\mathrm{N}$ que v]

Nótese que que es morfema gramatical que forma parte del SV cuyo núcleo es el verbo.

De manera similar, observamos que el signo que efectúa una transposición a la función adjetiva (de atributo) en (39)b., que tiene el mismo valor que (39)a.:

(39)a. El agua corriente

b. El agua que corre

La relativización equivale, por consiguiente, a la transposición del núcleo verbal a una función adjetiva; la operación se define en (40):

$$
\text { (40) }[\text { que } v] \rightarrow[\text { A que } v]
$$

En vista de los efectos distintos que se notan en (38) y en (40), debemos concluir que hay dos signos que, uno transpositor del núcleo verbal a la función nominal, otro transpositor del núcleo verbal a la función adjetiva. Hay otra distinción entre que nominal o anunciativo y que adjetivo o relativo. Que anunciativo agota su función en la mera transposición y "queda (...) al margen de las relaciones gramaticales de la oración transpuesta"'19.

Que relativo no sólo es transpositor, sino que también señala en la oración transpuesta "funciones cumplidas ordinariamente por sintagmas nominales a los que hace referencia"' (id.).

Junto a que relativo podemos hallar indicio de la función a que refiere: cero como sujeto, implemento o atributo; a como imple-

${ }^{18}$ La representación es mía y no forma parte del análisis de Alarcos, quien no presenta ningún formalismo.

19 Aldarcos, op. cit., p. 196. 
mento o complemento; otras preposiciones o $a$ como suplemento. Véase al respecto los ejemplos (41)a.-f.

(41)a. Las luces que brillaban (indicio: cero; función: sujeto)

b. La naranja que has comido (indicio: cero; función: implemento)

c. El chico que veis (indicio: cero; función: implemento)

$c^{\prime}$. El chico a quien veis (indicio: $a$; función: implemento)

d. Lo fuerte que es Juan (indicio: cero; función: atributo)

e. La persona a que enviaste recado (indicio: $a$; función: complemento)

f. El asunto de que hablé (indicio: preposición de; función: suplemento).

Se sigue de esto que la representación formal de la transposición adjetiva que efectúa que relativo, tal como se ha demostrado en (40), no es exacta; no se trata de un mero transpositor que, sino de una secuencia compuesta por el transpositor que y un indicio funcional F, que es cero, $a$ o P. La regla (40) debe ser modificada a la manera que mostramos en (42):

$(42)[\mathrm{F}+q u e \mathrm{~V}] \rightarrow\left[{ }_{\mathrm{A}} \mathrm{F}+q u e \mathrm{~V}\right]$, en que $\mathrm{F}=\{\varnothing, a, \mathrm{P}\}$

2.1.2. Observa Emilio Alarcos: "El relativo /que/, con sus variaciones, es, pues, un elemento transpositor a adjetivo, y a la vez un referente de sintagmas consabidos, como consecuencia de la refundición de dos posibles oraciones, con términos comunes, a una sola"'20. Se definen, pues, dos valores de que, a saber, el de transpositor y el de referente a sintagmas consabidos. El referente consabido, o sea, el antecedente, es un nombre; por tanto, a que relativo le debemos asignar valor nominal. Los indicios funcionales que acompañan a que relativo también suelen asociarse con nombres o sintagmas cuyo núcleo es un nombre.

Dada la circunstancia de que los indicios funcionales suelen asociarse con nombres y que la referencia a la función nominal suele efectuarse también mediante nombres, se sigue que que re- 
lativo tiene valor nominal, al mismo tiempo que es transpositor a la categoría de los adjetivos. Que relativo puede caracterizarse, pues, como un nombre gramatical con valor transpositivo a la categoría de los adjetivos.

2.1.3. Observa Alarcos que el indicio funcional que acompaña a que relativo forma parte de la cláusula relativa; con que nominal o anunciativo hallamos indicios funcionales que dependen del verbo subordinante, formando parte de la oración matriz. El contraste se observa en (43)a., b.:

(43)a. Se conforma con que le escuchen

b. He leído el libro con que se dio a conocer

En (43)a., el indicio funcional con depende de se conforma, el verbo principal, mientras que, en $(43) \mathrm{b}$., depende de se dio a conocer, complejo verbal de la cláusula subordinada. En las dos construcciones, con se asocia con una función nominal. No obstante, con que le escuchen cumple función nominal, mientras que con que se dio a conocer tiene función adjetiva respecto al antecedente $e l$ libro, al mismo tiempo que con que tiene función nominal respecto a se dio a conocer. Consideremos las estructuras categorizadas que se asignan a (43)a., b.:

(44)a. Se conforma [N [F $_{\mathrm{F}}$ con] [N que le escuchen]]

b. He leído $\left[_{\mathrm{N}}\right.$ el libro $\left[_{\mathrm{A}}\left[\mathrm{F}\right.\right.$ con] que $\left[_{\mathrm{V}}\right.$ se dio a conocer]]]

En (44)a., hallamos que anunciativo, que define una función nominal; en (44)b., hallamos que relativo, que define una función adjetiva. La diferencia, sin embargo, puede captarse de otra manera, como vamos a mostrar. En este aspecto, discrepamos de Alarcos, aunque nos atenemos a los principios del estructuralismo funcional. En (44)a., el verbo principal rige función nominal con indicio funcional con. En (44)b., el verbo principal rige función nominal con indicio funcional cero. A su vez, ésta se compone de un núcleo nominal, a saber, el antecedente de la cláusula relativa, seguido de un adyacente que puede analizarse como indicio funcional con asociado con la función nominal que, regidos por el verbo conocer. Se obtendría el análisis que mostramos en (45)a., b.:

(45)a. Se conforma [N [F con] [N que le escuchen]]

b. He leído $\left[_{\mathrm{N}}\right.$ el libro] $\left[_{\mathrm{N}}\left[\mathrm{F}\right.\right.$ con] $\left[_{\mathrm{N}}\right.$ que se dio a conocer]] 
La única diferencia entre (44) y (45) consiste en que el sintagma con que se dio a conocer se le asigna función adjetiva en $(44) \mathrm{b}$., mientras que se le asigna función nominal en (45)b.

De acuerdo con el análisis propuesto en (45)b., el indicio funcional se asocia con el verbo más cercano; la función adjetiva que cumple el sintagma con que se dio a conocer con respecto al antecedente el libro podría ser consecuencia, no del uso de que relativo, sino del uso de la preposición con. Ésta se halla también en construcciones tales como: el libro con la tapa azul, habilitando un nombre a la función adjetiva. Según este enfoque, es la preposición con la que es el transpositor del nombre, o sea la cláusula relativa, a la función adjetiva, interpretación que podría ser válida también en las cláusulas relativas introducidas por preposición, seguida de pronombre relativo distinto de que. No es necesario, pues, suponer que la transposición de las cláusulas relativas introducidas por preposición se deba al uso de los pronombres relativos, sino que podría considerarse la misma preposición como el transpositor a la función adjetiva. Su dependencia del verbo que se halla en la cláusula relativa sería fenómeno independiente, consistente en la transposición a la función nominal de la cláusula relativa, efectuada por el pronombre relativo. Las cláusulas relativas introducidas por que permitirían dos análisis opuestos: o bien tendrían un indicio funcional cero que podría ser considerado como transpositor a la función adjetiva, o bien se analizarían de la manera que se ha visto, siendo que transpositor a la función adjetiva. El primer análisis no puede explicar por qué se excluyen quien, el que y el cual de la posición indefensa, puesto que debería ser posible juntarlos con indicio funcional cero. El contraste que hay entre que, que se permite en posición indefensa no protegida por $\mathrm{P}$, y los pronombres relativos quien, el que, el cual, que no se permiten en posición indefensa, lleva a suponer que que relativo, a diferencia de quien, el que, el cual, es transpositor a la función adjetiva.

Por otra parte, en la secuencia: $\mathrm{P}+q u e$, al comienzo de una cláusula relativa, que no funciona como transpositor a la función adjetiva, valor asumido por $\mathrm{P}$, sino que es transpositor a la función nominal, al igual que quien, el que, el cual.

En resumidas cuentas, que "indefenso" debe ser interpretado como transpositor a la función adjetiva, como ha concluido Emilio Alarcos.

En la secuencia Preposición + pronombre relativo, el transpositor es la preposición; el pronombre relativo, al igual que que declarativo o anunciativo, debe ser interpretado como transposi- 
tor a la función nominal. Como hallamos que después de preposición alternando con el que, el cual y quien, se sigue que este que, aunque comparte con que "indefenso" el valor de relativo, se distingue de él en que es transpositor a la función nominal. No hay, por tanto, dos signos que, sino tres: uno transpositor a la función nominal, otro transpositor a la función adjetiva y el tercero transpositor a la función nominal al mismo tiempo que refiere a una función nominal en la cláusula que introduce. Esta distinción entre que "indefenso" y que "protegido"' por preposición, ambos con valor de relativo, es la modificación del análisis de Emilio Alareos que se impone.

2.1.4. Las secuencias introducidas por que relativo tienen función adjetiva. Hallamos nominalizaciones de esta función mediante el artículo $e l$, como en (46):

(46) El que estudia aprobará

La transposición a la categoría nominal se observa también con los adjetivos léxicos, como en (47):

(47) El lápiz verde $\rightarrow$ El verde

La interpretación formal de la transposición de una función adjetiva a la nominal se define en (48):

(48) $\mathrm{el} \mathrm{A} \rightarrow[\mathrm{N}$ el A]

La estructura que corresponde a (46) es, pues:

(49) [N el [A que estudia]] aprobará

Si este análisis fuese cierto, tendríamos que hallar ejemplos viables del tipo que se ejemplifica en (50):

(50) *E1 con que estudiará aprobará

No tiene explicación la no viabilidad de (50). Alarcos se limita a observar que es "prácticamente inusitada la sucesión inmediata de "artículo" y "preposición»"21.

2.1.5. Alternando con que relativo después de preposición hallamos el que, la que, los que, las que, lo que con el mismo valor relativo; el uso del artículo definido $e l$, la, los, las, lo no cambia el valor funcional de que relativo, de modo que se suspende el valor-

21 Ibid., p. 199. 
transpositivo que tienen los artículos definidos en otras circunstancias. La libre alternancia se observa en (51):

(51)a. El libro con que se dio a conocer b. El libro con el que se dio a conocer

Se trata, pues, de un artículo redundante que no tiene valor de transpositor y que no se puede identificar con el artículo no redundante del ejemplo (46), que sí tiene valor de transpositor. Con harta razón observa Alarcos que que "predomina en transposiciones sin preposición y es el único en las llamadas especificativas sin preposición'" (id.).

Nótese que, en el análisis de que propuesto en 1.4., el que relativo después de preposición es transpositor a la función nominal, como lo es el que en este contexto; en el análisis de Alarcos, tanto que como el que son transpositores a la función adjetiva. No obstante, en los dos análisis el es redundante puesto que el que tiene el mismo valor transpositivo que que.

2.1.6. El análisis de las cláusulas relativas que hemos emprendido en el apartado anterior coincide en algunos aspectos importantes con el de Alarcos. Por ejemplo, el doble valor de el que (pronombre relativo en unos casos, construcción compleja compuesta por el y el relativo que en otros) se reconoce en los dos análisis.

Los detalles de la transposición resultan un tanto confusos, ya que no se define con claridad cómo distinguir entre la transposición a la función nominal y la transposición a la función adjetiva. Acabamos de mostrar que la relativización mediante $\mathrm{P}+$ pronombre relativo se puede interpretar como una adjetivación efectuada por la preposición al mismo tiempo que la preposición se interpreta como un indicio funcional con respecto al verbo de la cláusula relativa. Conviene, pues, hacer una distinción entre dos procesos distintos de adjetivación, el uno mediante preposición, el otro mediante que.

En el apartado siguiente estudiaremos la transposición en un contexto más amplio, repasando los conceptos fundamentales del modelo estructural funcional e investigando de nuevo los fenómenos que no hallan cabida en él.

\subsection{Exposición del análisis estructural}

2.2.0. El concepto fundamental del modelo funcional es el de función. La unidad de análisis es la oración, que se define como una 
unidad independiente del discurso. En la oración, se descubren un núcleo verbal, los términos adyacentes del verbo, que cumplen distintas funciones, y otros sintagmas, los llamados adyacentes del predicado, que cumplen distintas funciones adverbiales o de complemento circunstancial. Los sintagmas adyacentes del verbo tienen una función nominal o adjetiva; el verbo es el sintagma nuclear del predicado. Las funciones nominales adyacentes del verbo son el sujeto, el implemento, el complemento y el suplemento, cada uno de los cuales puede ser identificado gracias a ciertas propiedades formales. Se definen tres categorías de palabras léxicas: nombres, adjetivos y verbos. Este sistema analítico permite trazar una distinción entre que anunciativo y que relativo, entre $e l$ que relativo y la secuencia el que compuesta por $e l$, transpositor a la función nominal, y que relativo.

2.2.1. El inventario restringido de conceptos analíticos del modelo tiene consecuencias para el análisis. En primer lugar, conviene señalar que la distribución de que, el que, quien, el cual, es tratada como "no pertinente", ya que no se puede describir con los medios analíticos disponibles en el modelo.

En segundo lugar, no se representa de una manera adecuada el concepto de referencia, tan fundamental en este tipo de construcciones, tanto por lo que se refiere a la "referencia a un sintagma consabido" como en lo concerniente a la función a que "refiere" el constituyente relativizado.

2.2.2. El relativo que no alterna con quien, el cual, el que si no va precedido de preposición. Este dato no puede ser descrito de una manera adecuada con los recursos analíticos que acabo de resumir, ya que, en este modelo, las preposiciones no constituyen clase léxica, sino que son tratadas como meros indicios funcionales, a veces con función de transpositores. En un principio, parecería como si se pudiera identificar una "función preposicional" equivalente a la "función adverbial", con lo cual se definiría una clase léxica de preposiciones. Alarcos se opone a esta interpretación arguyendo que las preposiciones tienen valor de indicio funcional solamente y que los adyacentes del predicado, que tradicionalmente se analizan como complementos adverbiales o circunstanciales, tiene función nominal. El argumento fundamental para rechazar la función preposicional, idéntica a la adverbial, consiste en la inexistencia de preposiciones independientes, con lo que queda excluida la posibilidad de interpretarlas como términos nucleares. 
Por consiguiente, las preposiciones no pueden ser consideradas como una clase léxica. Los adverbios tampoco constituyen una clase léxica, ya que las palabras tales como ayer, mañana, ahi, que tradicionalmente se interpretan como palabras con valor adverbial, se comportan como nombres, aunque constituyen una subclase especial. Se distinguen de los demás nombres en que no necesitan de una preposición para poder cumplir la función adverbial. Por ejemplo, son equivalentes entonces y en ese momento; el nombre momento puede cumplir función adverbial por el uso de la preposición en, frente a entonces, que reúne el valor de un nombre y el de un indicio funcional. De ser válidos estos argumentos, no tiene explicación la propiedad de los pronombres relativos según la cual se hallan sólo después de $\mathrm{P}$, puesto que la distinción entre SN y SP no puede tener pertinencia. La única manera de explicar la distribución de los pronombres relativos es suponer que los indicios funcionales $\mathrm{P}$ y $a$ se distinguen del indicio funcional cero. Supongamos que el supuesto indicio funcional cero sea, en realidad, inexistente; supongamos que no hay ningún indicio funcional cero. La ausencia de preposición equivale a la ausencia de indicio funcional. Si todos los pronombres relativos se toman por transpositores a la función nominal, la ausencia de preposición ante el pronombre relativo implica que la cláusula correspondiente tiene función nominal, haciendo imposible que obtenga función adjetiva.

La única manera de escapar a la no viabilidad es usar que, el único transpositor a función adjetiva. Ahora bien, aunque tiene explicación en cierta medida la distribución de que y los pronombres relativos, no se explica cómo la ausencia de indicio funcional le permite al constituyente relativizado "referir' ' a la función nominal pertinente en la cláusula relativa.

2.2.3. De acuerdo con el análisis de Alarcos, el sintagma relativo (el indicio funcional más el pronombre relativo) reúne tres valores: el de transpositor, el de referente a sintagmas consabidos y el de referente a la función que cumple el sintagma consabido en la cláusula relativa. El valor más misterioso sigue siendo el de transpositor; nótese que las cláusulas relativas siguen comportándose como cláusulas . Como los sintagmas relativos exhiben variación de número y género cuando se usa el que, etc., esta variación podría ser considerada como característica formal que comparten con los adjetivos. El signo invariable que debería interpretarse como amalgama con morfemas cero de número y género. De acuerdo 
con esto, deberíamos interpretar la construcción (52)a. de la manera que mostramos en (52)b.:

(52)a. Los chicos que llegaron

b. [N los chicos masc., plur.] [A que masc., plur. llegaron]

El valor transpositivo no residiría así en el uso de que u otros pronombres relativos, sino en la asociación de estos signos con los morfemas de número y género. No obstante, la variación de género y número se halla también en los nombres, de modo que el mismo argumento serviría para demostrar que no se trata de una transposición a la función adjetiva sino a la función nominal.

Los pronombres relativos, por su parte, tienen valor de referentes a sintagmas nominales "consabidos" en la gran mayoría de los casos, propiedad ésta de la categoría nominal. El indicio funcional que hallamos junto a los pronombres relativos también es propiedad de los nombres.

Basándonos en criterios estructurales, concluimos que tanto la variación de número y género como la capacidad que tienen los pronombres relativos de referir a un antecedente nominal permite su identificación como nombres, al mismo tiempo que se analizan como transpositores a la función nominal. No obstante, su falta de independencia no permite tratarlos como nombres léxicos.

Concluimos que los pronombres relativos son nombres dependientes, o sea, morfemas gramaticales que tienen la combinatoria sintáctica de los nombres léxicos. De manera similar, el relativo que, además de poder funcionar como pronombre relativo, alternando con el que, etc., puede analizarse como un adjetivo dependiente o gramatical, ya que no se asocia con preposición y es adyacente de un nombre. La falta de morfema de número y género supone una inmovilización comparable con la que se obser. va en los adverbios, si los comparamos con los nombres de adverbiales.

2.2.4. Aun así, los sintagmas relativos compuestos por una preposición y un pronombre relativo, aunque cumplen función nominal con respecto al verbo de la cláusula, habilitan la cláusula, que tiene núcleo verbal, a la función adjetiva. La paradoja de que una función nominal efectúa una transposición a la categoría adjetiva sigue en pie.

Es problemática también la transposición mediante el adjetivo gramatical que. El rechazo de los indicios funcionales característicos de la categoría de los nombres implica que se trata de un 
adjetivo gramatical capaz de referir a una función nominal "consabida" en la cláusula relativa. Se explica, pues, la transposición, pero queda por saber cómo se efectúa la referencia a la función gramatical del sintagma nominal consabido.

\subsection{Conclusiones}

La discusión del análisis estructural de las construcciones relativas ha permitido identificar dos problemas fundamentales, que son:

(i) la manera como opera la transposición en las cláusulas relativas introducidas por $\mathrm{P}+$ pronombre relativo;

(ii) la manera como se señala la función gramatical del sintagma nominal "consabido" en las cláusulas relativas introducidas por el adjetivo gramatical que.

El modelo funcional no permite presentar una explicación adecuada de los fenómenos que estamos sometiendo a investigación.

En el apartado siguiente, mostraremos que ciertos aspectos de la transposición también hallan cabida en el modelo generativo, en el que se resuelven algunas dificultades que han surgido en la descripción estructural.

3. LA ESTRUCTURA DE LOS SINTAGMAS ADJETIVOS Y LA ADJETIVACIÓN DE LA CLÁUSULA RELATIVA INTRODUCIDA POR "QUE": ANÁLISIS GENERATIVO

\subsection{Introducción}

En este apartado se expondrá la adjetivación de la cláusula relativa introducida por que en términos generativos.

En la primera sección estudiaremos la estructura de los sintagmas adjetivos (abreviados SA) para poder formarnos una idea más clara de sus propiedades sintácticas. Respecto a la estructura de $\mathrm{SA}$, intentaremos demostrar que contienen, por lo general, un $\mathrm{SN}$ vacío que es el complemento sintáctico de $\mathrm{A}$. Hablando más en concreto, sostendremos que ejemplos tales como (53)a. tienen la estructura que detallamos en (53)b.:

(53)a. La mañana es hermosa

b. [SN la mañana] [Sv [V es [SA [A hermosa] [SN $e]]]]$

En la segunda sección, se hablará de la supuesta adjetivación de las cláusulas relativas introducidas por que en posición inde- 
fensa. Se verá que el concepto de adjetivación puede ser incorporado en la teoría generativa. No obstante, la base empírica de esta aproximación a las cláusulas relativas resultará ser inadecuada.

\subsection{La estructura de los sintagmas adjetivos}

3.1.0. Al igual que las demás categorías léxicas $\mathrm{N}, \mathrm{V}$ y $\mathrm{P}$, los adjetivos (A) pueden regir complementos de la categoría SP, como se observa en los ejemplos (54)a.-c.:

(54)a. Contento con la vida

b. Fiel a los amigos

c. Orgullosos de sus éxitos

En español, no hallamos complementos de la categoría SN si el núcleo es A. En este aspecto, A se parece a N, que tampoco admite complementos de la categoría SN, y se distingue de $\mathrm{P}$ y V, que sí los admiten. Esta configuración de datos se explica en la teoría generativa actual de la manera siguiente: $\mathrm{SN}$, o su núcleo $\mathrm{N}$, debe ser marca de Caso, rasgo abstracto que no tiene realización fonética en español, o sea, que es invisible ${ }^{22}$. La marca de Caso no es propiedad inherente de $\mathrm{N}$, sino que se trata de un rasgo que le debe ser asignado en ciertos contextos sintácticos. Los contextos sintácticos en los que se asigna marca de Caso a N (o a SN) se definen de la manera siguiente: SN recibe marca de Caso si es término de una preposición, complemento directo de un verbo transitivo o sujeto sintáctico de un verbo finito. En términos más técnicos, se dice que $\mathrm{SN}$ recibe marca de Caso si es regido por P, V o INFL, la terminación del verbo finito. Si SN es regido por A o N, no recibe marca de Caso, lo cual tiene como consecuencia que SN desprovisto de marca de Caso es inadmisible.

Nótese que la explicación es indirecta, ya que se sigue de dos reglas relativamente independientes, que son:

${ }^{22}$ La marca de Caso, o mejor dicho, las distintas marcas de Caso, tienen expresión fonológica en otras lenguas, tales como el latín y el alemán. Como no la tienen en español, las trato como un solo rasgo abstracto, que puede ser interpretado como un puro formalismo mediante el cual se describe la distribución de SN. Véase también J. Schroten, "Marking Rules and the Underlying Order of Constituents in Spanish", en W. Zonneveld y F. Weerman (eds.), Linguistics in the Netherlands 1976-1977, Amsterdam, 1978. 
(55)a. Son agramaticales las oraciones en que se halla un SN léxico (o sea, no nulo) desprovisto de marca de Caso.

b. SN obtiene marca de Caso si es regido por P, V o INFL.

La imposibilidad de que $\mathrm{N}$ y A tengan complemento de la categoría SN se interpreta, pues, como consecuencia de su incapacidad de asignar marca de Caso. La observación se repite en (56):

(56) N y A son incapaces de asignar marca de Caso, por lo que no admiten complementos léxicos de la categoría SN.

Nótese que los complementos de la categoría SN se admiten con A si se trata de un complemento no léxico o nulo o si SN es capaz de recibir marca de Caso de otra manera, o sea, de un elemento diferente de A. Esta observación se halla en:

(57) Se rechaza la configuración: [A SN...]

salvo si SN es categoría vacía o si recibe marca de Caso.

Como son más fáciles de estudiar los constituyentes lexicalizados que los vacíos, pasamos a demostrar primero que el SN complemento de A se salva en algunas circunstancias en las que SN recibe marca de Caso de un elemento que se halla fuera de SA. Esto se tomará como prueba de que A suele tener como complemento nominal la categoría vacía.

\subsubsection{Consideremos los ejemplos (58)a., b.:}

(58)a. Sano tu novio, podrás hablar libremente

b. Enfermo yo, tú debes ganar el dinero

Las construcciones llamadas absolutas, sano tu novio en (58)a. y enfermo yo en (58)b., han sido el tema de mucha discusión ${ }^{23}$. Desde un punto de vista interpretativo, los SN tu novio y yo son los "sujetos lógicos" y los adjetivos sano y enfermo son los predicados. Es sorprendente que el orden: predicado + sujeto es el que se prefiere con mucho al inverso, que presentamos en (59):

(59)a. *Tu novio sano, podrás hablar libremente b. *Yo enfermo, tú debes ganar el dinero

${ }^{23}$ El estudio más detallado es el de S. Gutiérrez Ordóñez, "Construcciones atributivas absolutas", Verba, 5 (1978), 305-314. 
Otra propiedad sorprendente es la falta de verbo; a veces se sugiere que se trata de la reducción mediante elisión del verbo copulativo en oraciones tales como (60)a., b.:

(60)a. Estando sano tu novio, podrás hablar libremente b. Estando enfermo yo, tú debes ganar el dinero

La hipótesis es difícil de sostener, puesto que el orden fijo de A y SN que observábamos en (58), (59) no se da si el verbo está presente:

(61)a. Estando tu novio sano, podrás hablar libremente b. Estando yo enfermo, tú debes ganar el dinero

Las construcciones absolutas (58)a., b., podrían ser analizadas como en (62)a., b., respectivamente:

$$
\text { (62)a. [SA sano] [SN tu novio] }
$$

b. [SA enfermo] [SN yo]

Este análisis es insuficiente, puesto que la preferencia de la posición postadjetiva por parte de SN no tiene explicación. Supongamos que tienen la estructura (63)a., b.:

(63)a. [SA [A sano] [SN tu novio]]

b. [SA [A enfermo] [SN yo]]

El "sujeto interpretativo"' de la construcción absoluta se analiza, pues, como el complemento sintáctico de A.

El análisis explica el orden preferido. Como SN es el complemento de A, debe seguirlo, como es usual en español. Recuérdese que también los complementos de $\mathrm{P}$ deben seguir a su núcleo $\mathrm{P}$.

Se observa lo mismo con respecto a los complementos de $\mathrm{V}$ y $\mathrm{N}$, que siguen a su núcleo. El fenómeno es tan general que sería ocioso dar largas series de ejemplos con cada una de las categorías léxicas. Nos limitamos a mostrar los ejemplos con núcleo adjetivo:

(64)a. *Con la vida contento

b. ${ }^{*}$ A sus amigos fiel

c. *De sus éxitos orgulloso

Es válido, por consiguiente, el postulado que proponemos en (65):

(65) En español los complementos siguen a los núcleos de que dependen. 
El análisis propuesto en (63) explica el orden preferido que se halla en las construcciones absolutas, razón por la cual merece ser estudiado con mayor detenimiento.

3.1.2. Según la teoría de los Casos, el SN de las construcciones absolutas debería recibir marca de Caso. El ejemplo (58)b. demuestra que recibe el Caso nominativo: yo es el pronombre personal nominativo ${ }^{24}$. ¿Cómo se explica esto? No conviene suponer que en estas circunstancias A se convierte en asignador del Caso nominativo, puesto que esto dejaría sin explicar la incapacidad, de parte de A, de asignar marca de Caso en otras circunstancias. Normalmente, INFL, la terminación del verbo finito, asigna marca de Caso nominativo al SN que lo precede; INFL se compone de TMP y AGR, los morfemas de tiempo/aspecto/modo y de número/persona. Como los adjetivos tienen morfemas de número y género, no sería descabellado suponer que A se compone de A y AGR, de modo que el análisis de las construcciones absolutas podría basarse, tal vez, en la estructura (66), que adoptamos como primera aproximación:

$$
\text { (66) }[\mathrm{SA}[\mathrm{A} \mathrm{A}+\mathrm{AGR}] \mathrm{SN}]
$$

Convendría hallar un morfema comparable con TMP, o sea, un morfema que indique "tiempo", fundamentalmente. Es de cierto interés observar que muchas construcciones absolutas van introducidas por la locución adverbial con valor "temporal" una $v e z$, como en (67):

(67)a. Una vez sano tu novio

b. Una vez enfermo yo

En realidad, son más corrientes las construcciones absolutas introducidas por una vez que las que carecen de este adverbio. Estipulamos que la categoría vacía correspondiente está presente en los casos en que falta una vez. El análisis de (58)a., b., que adoptamos por ahora es, pues, el que se halla en (68)a., b.:

${ }^{24}$ Los pronombres personales permiten una distinción entre la marca de Caso que recibe SN en la posición del sujeto sintáctico y la que recibe como término de una posición. Se trata, pues, de la marca de Caso que asignan INFL y $\mathrm{P}$ respectivamente. Las denominaciones corrientes son Caso nominativo para el que asigna INFL y Caso oblicuo para el que asigna P. Además, se suele decir que $\mathrm{V}$ asigna Caso acusativo. Para un análisis más detallado véase $\mathrm{J}$. SHROTEN, "Marking Rules..." 
(68)a. [SA [TMP $e][\mathrm{A}$ san- + AGR] [SN tu novio]]

b. [SA [TMP $e][\mathrm{A}$ enferm- + AGR] [SN yo]]

El constituyente gramatical simbolizado por AGR tiene valor nominal, asociándose con $\mathrm{SN}$, de la misma manera que en las oraciones finitas el sujeto se asocia con AGR. La nueva manera de asignar la marca de Caso al sujeto sintáctico se define en (69):

(69) SN recibe marca de Caso si va regido por TMP y AGR.

En apoyo del análisis de las construcciones absolutas que acabamos de proponer, mostraremos que hay otras construcciones en las que $\mathrm{SN}$ es el complemento sintáctico de A y recibe marca de Caso de parte de un elemento que se halla fuera de SA.

\subsubsection{Consideremos los ejemplos (70)a., b.:}

(70)a. Encuentro fea la pintura

b. Encuentro la pintura fea

En (70)a., b., fea es el atributo del complemento directo la pintura. Observamos que se prefiere, o se admite como natural, el orden A + SN, aunque no se excluye el orden inverso. Los análisis convencionales sostienen que se trata de una construcción en que el verbo encuentro tiene dos complementos: uno directo y el otro atributivo. No obstante, es sorprendente que el orden A + $\mathrm{SN}$ sea tan natural como el orden $\mathrm{SN}+\mathrm{A}$. En cambio en construcciones aparentemente similares, ejemplificadas en (71), hallamos una preferencia acusada por el orden SN + A:

(71)a. Comí la carne cruda

b. *Comí cruda la carne

Hay alguna vacilación respecto a (71)b., puesto que podría ser aceptable con acentuación especial, pero es indudable que el orden más natural se da en (71)a. ¿A qué se debe el contraste entre (70) y (71)?

Observemos que no cambia el sentido de (71)a. si suprimimos el adjetivo; cf. (72)a. En (70), en cambio, si se suprime el adjetivo, queda alterado el sentido de la construcción:

(72)a. Comí la carne

b. Encuentro la pintura

La distinción se aprecia mejor si usamos creer en vez de encontrar:

(73)a. Creo malograda tu tentativa

b. *Creo tu tentativa 
Intuitivamente hablando, diríamos que encontrar y creer rigen un solo complemento complejo compuesto por A y SN, mientras que comer rige un solo complemento de la categoría $\mathrm{SN}$ a la que se añade un SA facultativo. Hay más: la secuencia compuesta por encontrar o creer y A forma una sola unidad semántica que tiene como complemento directo el SN, mientras que comer y A no constituyen ninguna unidad semántica. Es decir que parece ser correcto el análisis interpretativo (74)a., mientras que no lo es (74)b.:

$$
\begin{aligned}
& \text { (74)a. (v encuentro + fea) la pintura } \\
& \text { b. * (v comí + cruda) la carne }
\end{aligned}
$$

De hecho, hallamos muchos verbos léxicos que se interpretan de la manera que se muestra en (74)a., pero no hay ninguno comparable con (74)b. Así, tenemos verbos como detestar, apreciar, empobrecer, que se analizan como hallar detestable, hallar apreciable, hacer pobre. Esto sugiere que hay una clase de verbos, como encontrar, hallar, hacer, creer, tener, que rigen SA, el cual, a su vez, se compone de A y SN. Se hallan algunos ejemplos particularmente convincentes en (75):

(75)a. Hacemos felices a los huérfanos

b. Tenemos listas las maletas

c. Creemos ineficaces las medidas

d. Dejamos inacabado el trabajo

e. Ponemos loco a su hijo

f. Estimamos conveniente su reemplazo

La estructura pertinente de estos ejemplos se ve en (76):

(76) $\left[\mathrm{sV} \mathrm{V}\left[\mathrm{SA} \mathrm{A} \mathrm{N}^{\prime \prime}\right]\right]$

El análisis (76) explica por qué, en este tipo de construcciones, es natural el orden A + SN: SN es el complemento sintáctico de $A$, por lo que es natural que lo siga. SN no recibe marca de Caso de parte de A, pero sí de V. De hecho, todos los verbos que constituyen esta clase son transitivos, de modo que tienen la capacidad de asignar marca de Caso a SN. Lo curioso es que no la asignen a su propio complemento sintáctico, sino al complemento de A.

3.1.4. Los SN léxicos se hallan como complementos de $\mathrm{A}$ en algunas circunstancias excepcionales; conviene investigar, pues, si A tiene generalmente $\mathrm{SN}$ vacío en los casos en que SN no puede 
recibir marca de Caso. Consideremos al respecto el ejemplo (53)a. y la estructura correspondiente (53)b.:

(53)a. La mañana es hermosa

b. [SN la mañana] [SV [V es [SA [A hermosa] [SN $e]]]]$

De nuevo, el orden en que se da SN y su atributo A en los casos en que los dos están en posición postverbal constituye un argumento a favor de la hipótesis que acabamos de proponer; cf. (77)a., b.:

(77)a. Es la mañana hermosa

b. Es hermosa la mañana

Es notable que (77)b. constituya un orden más natural que (77)a.; esto sugiere que (77)b. tiene una estructura menos compleja que (77)a. Las estructuras que se pueden asignar según nuestra hipótesis se muestran en (78)a., b.:

(78)a. [V es] [SN la mañana] [SA [A hermosa] [SN $e]]$

b. [V es] [SN [A hermosa] [SN la mañana]]

Observamos que la estructura (78)b., que corresponde a (77)b., es menos compleja que (78)a., que corresponde a (77)a. Se sigue de esto que nuestra hipótesis queda confirmada, ya que la estructura menos compleja sintácticamente es, de hecho, la más natural. ¿Cómo recibe marca de Caso el SN la mañana en (53)a. y en (77)a., b.? En (53)a. se halla en la posición del sujeto sintáctico del verbo finito, junto a INFL, y recibe marca de Caso de la manera usual. Respecto a (77)a., b., suponemos que la marca de Caso es transmitida a SN a través de la posición vacía del sujeto ${ }^{25}$; esta posición no la hemos indicado en (78).

3.1.5. La interpretación de cómo se asigna Caso en las construcciones de las que acabamos de hablar tropieza con una dificultad grave que conviene exponer.

El núcleo que asigna Caso a su complemento debe regirlo en sentido jerárquico ${ }^{26}$. Esta observación es trivial, ya que se consi-

${ }^{25}$ En L. Burzıo, Intransitive Verbs and Italian Auxiliaries, tesis doctoral, Massachusetts Institute of Technology, Cambridge, 1981, se halla un sistema de reglas de asignación de la marca de Caso nominativo que permite esta operación; remitimos a este estudio para los detalles formales.

${ }^{26}$ Se trata de una relación jerárquica denominada "rección"; cf. $\mathrm{N}$. Chomsky, Lectures on Government... e infra, apartado 4. 
deran como complementos los constituyentes regidos por el núcleo. Ha sido propuesta ${ }^{27}$ otra condición de más interés; ésta se halla en (79):

(79) El sN que recibe marca de Caso debe hallarse al lado del núcleo del que la recibe.

Es decir que, si $\mathrm{X}$ es el elemento que asigna Caso a SN, se admiten las secuencias: ... X SN ..., o: ...SN X...28, pero si se halla un constituyente separando X de SN, es imposible que SN reciba marca de Caso de X. Esta Condición de Adyacencia es también válida en español, como pasamos a demostrar.

La validez de la condición es obvia si $\mathrm{X}=\mathrm{P}$, puesto que ningún constituyente puede separar $\mathrm{P}$ de su complemento:

(80)a. Con las manos en los bolsillos $/{ }^{*}$ Con en los bolsillos las manos

b. Con la cara crispada / Con crispada la cara

La única excepción aparente se halla en (81):

(81)a. *Después de la cena lista / Después de lista la cena

b. *Antes de la cena lista / Antes de lista la cena

Se trata de construcciones absolutas introducidas por después de, antes de cumpliendo la misma función que una vez. Por lo visto, se comportan como la categoría TMP y no como P.

La Condición de Adyacencia parece que se suspende si $\mathrm{X}=$ $\mathrm{V}$, en cuyo caso SN es el complemento directo. En los ejemplos siguientes, que son perfectamente aceptables, $\mathrm{V}$ y SN no se hallan el uno al lado del otro, sino que están separados por otro constituyente:

(82)a. Entregó a los alumnos las estampillas

b. Abrió con llave la puerta

c. Pronunció con esmero las palabras

${ }^{27}$ La propuesta se debe a T. STOwELL, Origins of Phrase Structure, tesis doctoral, Massachusetts Institute of Technology, Cambridge, 1981.

${ }^{28}$ Como los complementos siguen a su núcleo en español, véase (65) en 3.1.1., la marca de Caso suele asignarse al SN que está a la derecha del núcleo. De esto se sigue que es una característica específica del español el que se excluyan en la práctica las secuencias ... SN X ... La única excepción es INFL, que según parece asigna la marca de Caso al SN que está a su izquierda. Sugeriremos, al final de esta subsección 3.1.5., una solución que permite sostener que esta excepción es solamente aparente. 
No cabe duda que (82)a.-c. son aceptables y comunes. Si no estamos dispuestos a estipular que la Condición de Adyacencia queda suspendida si $\mathrm{X}=\mathrm{V}$, suspensión arbitraria $\mathrm{y}$, por ende, difícil de aceptar, se nos impone investigar cómo $\mathrm{V}$ podría sustraerse a la condición. Notemos primero que los efectos de la Condición de Adyacencia (79) se detectan en los ejemplos siguientes, en que la posición natural del complemento directo es la adyacente al verbo:

(83)a. Apoyó la mesa a la pared / ?Apoyó a la pared la mesa

b. Echó el papel en el suelo / ?'Echó en el suelo el papel

Ahora bien, la clave de la aparente suspensión se halla en ejemplos tales como (84) en que es tan natural el orden $\mathrm{V}+\mathrm{Y}+\mathrm{SN}$ como el orden $\mathrm{V}+\mathrm{SN}+\mathrm{Y}$, en que $\mathrm{Y}$ es un constituyente y $\mathrm{SN}$ el complemento directo de $\mathrm{V}$ :

(84)a. Dejé [y atrás] el libro / Dejé el libro atrás

b. Dejé [y de lado] este problema / Dejé este problema de lado

c. Eché [y encima] una piedra / Eché una piedra encima

d. Tengo [y a mi disposición] varias medidas / Tengo varias medidas a mi disposición

En estos ejemplos, las secuencias $\mathrm{V}+\mathrm{Y}$ constituyen locuciones verbales idiomáticas; $\mathrm{SN}$ es el complemento directo de la locución verbal entera. Esto sugiere que la secuencia compuesta por un verbo transitivo y $\mathrm{Y}$ se reanaliza como un complejo verbal transitivo [ $\mathrm{V} \mathrm{V}+\mathrm{Y}]$; por lo visto, es el complejo verbal el que asigna marca de Caso al complemento directo, obteniendo la transitividad del $\mathrm{V}$ incluido en él ${ }^{29}$. Volviendo a los ejemplos (82) a.c., observamos que es posible adoptar la misma solución: la secuencia $\mathrm{V}+\mathrm{Y}$ se reanaliza como un complejo verbal transitivo, de la manera que indicamos en (85):

(85)a. [V [V entregó] [Y a los alumnos]] las estampillas

b. [V [V abrió] [Y con llave]] la puerta

c. [V [v pronunció] [y con esmero]] las palabras

${ }^{29}$ Las reglas de reanálisis se defienden en A. Marantz, On the Nature of Grammatical Relations, tesis doctoral, Massachusetts Institute of Technology, Cambridge, 1981, donde se intenta dar una justificación interesante. Hay que tener en cuenta que lo que proponemos aquí es una extensión de T. STOWELl, op. cit. 
Conviene tener en cuenta que el complejo verbal compuesto por $\mathrm{V}$ y $\mathrm{Y}$ debe ser interpretable como una unidad semántica natural. En general, el complejo verbal es más natural si Y representa el modo de efectuarse la acción designada por $\mathrm{V}$ o si $\mathrm{Y}$ representa un aspecto del significado verbal. El problema de saber si se admite el reanálisis o no es delicado y requiere un estudio más detenido del que podemos ofrecer en este momento ${ }^{30}$.

Considérense los efectos de la Condición de Adyacencia en los ejemplos siguientes:

(86)a. ?? Dejé de lado ayer este problema

b. ?? Encontré en la calle ayer estas monedas

c. ??Entregué a los alumnos ayer las estampillas

Este tipo de datos sugiere que los complejos verbales reanalizados tienen que hallarse al lado del complemento y que la "intromisión" de otro constituyente entre el complejo verbal y su complemento directo va en detrimento de la naturalidad. El fenómeno es particularmente acusado si se juntan un complemento circunstancial locativo y otro temporal, como en (87):

(87)a. ??Entregué a los alumnos en la calle ayer las estampillas

b. ?? Abrí a las ocho en mi oficina la puerta con llave

Los efectos de la Condición de Adyacencia se notan muy indirectamente, dada la libertad que tiene el español de formar complejos verbales mediante reanálisis. Estos asignan marca de Caso al complemento directo, que se halla adyacente al complejo verbal, pero no al verbo transitivo que es su núcleo. Se sigue, pues, que la Condición de Adyacencia es válida en español, tanto si $\mathrm{x}$, el elemento que asigna Ciaso, es $\mathrm{P}$ como si es V. Los efectos son menos visibles si $\mathrm{X}=\mathrm{V}$, ya que se halla una interacción con la regla de reanálisis. Si se da como válida la Condición de Adyacencia en español, se impone la necesidad de dar otra interpretación a la manera como INFL asigna marca de Caso al sujeto del verbo finito.

La asignación de la marca de Caso opera, como se supone, en la estructura SN - INFL ..., en que SN es regido por INFL y se halla a su lado. INFL está compuesto por TMP y AGR, elemento (pro)nominal. Cabe considerar, pues, otra interpretación según

${ }^{30} \mathrm{El}$ reanálisis de la secuencia compuesta por $\mathrm{V}$ y el complemento indirecto, como en (85) a, no puede aceptarse con mucha confianza; no debería causar gran sorpresa descubrir que requiere tratamiento distinto. 
la cual es AGR el "nombre", que recibe marca de Caso. Como AGR no es nombre léxico, es incapaz de retener el Caso, de modo que lo transmite al SN con que se asocia, o sea, el sujeto léxico SN. Esta interpretación tiene la ventaja de que AGR, siendo complemento sintáctico de TMP, recibe de él marca de Caso; AGR compartiría con los demás complementos la propiedad de que sigue a su núcleo. Lo excepcional estaría en que AGR transmite marca de Caso al sujeto de la categoría SN, por su carácter excepcional de nombre gramatical incapaz de retener la marca de Caso. Esto explicaría, a su vez, la movilidad del sujeto sintáctico, puesto que no es necesario que la transmisión del Caso obedezca a la Condición de Adyacencia. Adoptando por el momento la hipótesis, decimos que TMP asigna marca de Caso a AGR; éste lo transmite al sujeto léxico. La hipótesis será modificada un poco, pero la idea básica de que TMP es el constituyente que asigna Caso al SN que se halla a su derecha y que es contiguo a él (que es normalmente AGR) seguirá siendo válida.

3.1.6. Una vez admitida la validez con la Condición de Adyacencia se nos presenta un problema concerniente al análisis de las construcciones absolutas y las que se componen de un verbo transitivo del tipo encontrar con complemento de la categoría SA. La estructura de las construcciones absolutas que hemos propuesto se presenta en (88):

$$
\text { (88) }\left[\mathrm{SA}_{\mathrm{A}} \mathrm{TMP}[\mathrm{A} \mathrm{A}+\mathrm{AGR}] \mathrm{SN}\right]
$$

Obsérvese que TMP no se halla al lado de AGR, sino que queda separado de él por una palabra de la categoría A.

Fenómeno similar detectamos en el segundo tipo de construcciones encabezadas por encontrar y verbos parecidos, que tendrían la estructura (89):

$$
\text { (89) [SV V [SA A SN]] }
$$

En este caso, la paradoja se soluciona suponiendo que la secuencia $\mathrm{V}+\mathrm{A}$ se reanaliza como un complejo verbal transitivo. La estructura pertinente en el momento de asignarse el Caso se presenta en (90):

$$
\text { (90) }[\mathrm{SV}[\mathrm{V} \mathrm{V}+\mathrm{A}] \mathrm{SN}]
$$

Las construcciones absolutas representadas en (88), según podemos suponer, también se reanalizan, actuando TMP como el núcleo del "TMP complejo", que asigna la marca del Caso nominativo a SN. Es ocioso estipular que AGR forma parte de A, 
puesto que la configuración obtenida en (91), después de reanálisis, satisface las exigencias según las que TMP debe hallarse al lado de SN para asignarle marca de Caso:

$$
\text { (91) [TMP TMP + A] SN] }
$$

La nueva hipótesis no sólo permite descartar la estipulación de que AGR forma parte de A, sino que también hace superfluo el postulado poco fundado de que sólo AGR puede recibir marca del Caso de TMP. De hecho, TMP asigna Caso a todo SN que se halle regido por él y que esté a su lado; en las oraciones con verbo finito, es fenómeno accidental el que AGR sea, por lo general, el único nombre capaz de satisfacer las dos exigencias.

En las construcciones absolutas en que TMP se reanaliza como un complejo temporal constituido por TMP y A, el SN complemento de A satisface las exigencias, sin que sea necesario estipular que AGR forma parte de los adjetivos. En ellas, TMP asigna Caso directamente a SN. Veremos luego que hay otras circunstancias en que TMP asigna marca de Caso a SN y no a AGR.

La regla de reanálisis puede interpretarse como un cambio estructural del tipo que se halla en (92)a., o como una adjunción del tipo que se ve en (92)b.:

$$
\begin{aligned}
& \text { (92)a. X Y } \rightarrow[\mathrm{X} X \mathrm{Y}] \\
& \text { b. } \mathrm{XY} \rightarrow[\mathrm{X} X \mathrm{Y}]\left[{ }_{\mathrm{Y}} e\right]
\end{aligned}
$$

Parece más apropiada la regla formulada en (92)b., puesto que se supone que las reglas de adjunción normalmente crean una estructura derivada con un nuevo nudo de la misma categoría, como en (92)b.; éste sirve de "lugar de aterrizaje" del constituyente que se adjunta. El constituyente adjuntado no se halla necesariamente al lado de $\mathrm{X}$, como es lógico suponer para las construcciones del tipo dejar de lado, meter en cintura, pasar por alto. La posición que deja vacía el constituyente adjuntado $Y$ no se suprime, sino que contiene la categoría vacía, por lo que no es necesario que reciba marca de Caso, aunque debe satisfacer otras condiciones que no son objeto de este trabajo.

En definitiva, se obtienen las configuraciones (93)a., que representa la estructura reanalizada de las construcciones absolutas y (93)b., que es representación de las construcciones encabezadas por encontrar y verbos similares:

$$
\begin{gathered}
\text { (93)a. }[\mathrm{SA}[\mathrm{TMP} \mathrm{TMP}+\mathrm{A}][\mathrm{A} e] \mathrm{SN}] \\
\mathrm{b} \cdot[\mathrm{SV}[\mathrm{V} \mathrm{V}+\mathrm{A}][\mathrm{SA}[e] \mathrm{SN}]]
\end{gathered}
$$


El Caso se asigna a través de la categoría vacía, constituyente "invisible", a este respecto.

3.1.7. El análisis que hemos obtenido en (93) tiene consecuencias interesantes para el análisis de las oraciones subordinadas que funcionan como sujeto de un Sintagma Verbal compuesto por la cópula ser y un adjetivo, del tipo que se halla en (94):

(94) Es fácil que lo hagan

Sin duda alguna, que es una conjunción nominal y debe recibir Caso ${ }^{31}$. Los análisis tradicionales sugieren que la oración subordinada se asocia con un pronombre cero en posición de sujeto del verbo finito, como en (95):

(95) pro es fácil [que lo hagan]

La conjunción nominal que recibiría marca de Caso de parte de pro, que a su vez ha recibido el Caso de AGR. No obstante, constituye un problema difícil el análisis de la construcción emparentada que ejemplificamos en (96):

(96) Creo fácil que lo hagan

La conjunción nominal que debe recibir marca de Caso. No es posible que la herede de un pronombre objeto elidido, puesto que los pronombres objeto no se eliden en español, a diferencia de los pronombres sujeto que sí pueden ser suprimidos. Tampoco es posible usar un pronombre lexicalizado, como en (97):

(97) * Lo creo fácil que lo hagan

Adoptando el análisis propuesto en (93)b., hallamos que (96) tiene la estructura reanalizada (98) en el momento de aplicarse la regla de asignación del Caso:

(98) $[\mathrm{SV}[\mathrm{V}$ creo [A fácil]] [SA [ A e] [o' que [o lo hagan]]]]

${ }^{31} \mathrm{El}$ argumento más fuerte es que las oraciones finitas subordinadas se comportan como SN por lo que se refiere a la teoría del Caso, admitiéndose después de $\mathrm{P}$ y $\mathrm{V}$, pero después de $\mathrm{N}$, a no ser que $\mathrm{N}$ vaya seguido de $\mathrm{P}$; véase al respecto (i)-(iii):

(i) Aplauden que hayas venido

(ii) Vinieron sin que nos hubieran avisado

(iii) El rumor de que vengan ha resultado ser infundado

Como la oración subordinada se comporta como SN que "anunciativo" (término de Alarcos) se puede interpretar como nombre léxico que necesita marca de Caso; véase también J. Shroten, "Two Approaches to the Distribution..." 
El complejo verbal creo fácil es transitivo y asigna el Caso acusativo a que, de modo que no se requiere ninguna estipulación especial. Consideremos de nuevo el ejemplo (94), construcción unipersonal en que es dudoso que haya $\mathrm{AGR}^{32}$. Nótese al respecto que la coordinación de dos oraciones sujeto no tiene efecto por lo que se refiere al número del verbo finito, lo que constituye una prueba clara a favor de la hipótesis de que falta AGR:

(99) Es (*son) fácil (* fáciles) que lo hagan y que nosotros lo tengamos que deshacer

Suponiendo que (94) no tiene AGR, pero sí TMP, podemos analizarlo de la siguiente manera: hagan]]]]]

(100) [o' TMP [sv [v es] [sa [a fácil] [o, que [o lo

En esta estructura se obtiene un reanálisis de $\mathrm{V}+\mathrm{A}$, dando un verbo complejo: [v es fácil]. Es obvio que TMP y el verbo complejo ser fácil se combinan formando un solo constituyente. Hay dos posibilidades: se obtiene el constituyente reanalizado: [TMP TMP [V es fácil]], capaz de asignar marca de Caso a que, o bien TMP se incorpora al verbo, dejando a éste su capacidad de asignar el Caso nominativo. Las dos posibilidades arrojan el mismo resultado, de modo que no nos importa saber cuál sea la más apropiada.

En resumidas cuentas, el análisis propuesto en (93)a., b. permite una explicación de las construcciones del tipo (94) y (96).

3.1.8. La construcción de un sistema que explique el comportamiento sintáctico de SA ha sido más ardua de lo que parecía a primera vista. De hecho, los argumentos manejados al principio han resultado ser engañosos, puesto que la solución que nos vemos forzados a adoptar se aparta bastante del análisis que creíamos apropiado en un principio. Revisemos los puntos más importantes.

El hecho fundamental es que A no asigna marca de Caso en ningún momento de la derivación. Sólo asignan Caso V, P y TMP. De la incapacidad de A de asignar Caso a SN se sigue que no puede tener complemento léxico de la categoría SN. Como los complementos, en español, siguen al núcleo, concluimos que no es viable la estructura [SA A SN ...].

Hay dos maneras de evitar el rechazo de [SA A SN ...]. En pri-

32 Véase al respecto la argumentación de J. Schroten, "Subject Deletion or Subject Formation: Evidence from Spanish", LingA, 7 (1981), 121-169. 
mer lugar, SN puede representar la categoría vacía, ya que ésta no requiere Caso. En segundo lugar, SN podría recibir marca de Caso fuera de SA. La invisibilidad de la categoría vacía hace poco provechosa la investigación de sus propiedades si éstas no se pueden comparar con las de SN léxico. Conviene, por tanto, estudiar las construcciones en que SN en SA obtiene Caso fuera de SA.

Importa tener en cuenta que es imposible sostener que A deja pasar la marca de Caso en la configuración: ...X ...[SA A SN ...], donde $\mathrm{X}=\mathrm{P}, \mathrm{V}$ o TMP. Si esto fuese cierto, no habría manera de excluir construcciones del tipo *comer cruda la carne o *con alzada la cabeza, que podrían siempre analizarse como secuencias de $\mathrm{X}(\mathrm{X}=\mathrm{V}$ o $\mathrm{P})$ que rigen $\mathrm{SN}$ en $\mathrm{SA}$.

Se complica el problema en el momento en que nos damos cuenta de que la Condición de Adyacencia es válida también en español, pese a las muchísimas excepciones aparentes. De acuerdo con esta condición, X sólo asigna Caso a SN si éste se halla a su lado.

A primera vista, debemos concluir que SN en SA nunca obtiene marca de Caso, puesto que cualquier $\mathrm{X}$ fuera de SA tropieza con la presencia de A entre $\mathrm{X}$ y SN, como es obvio. Las excepciones a la Condición de Adyacencia que hallamos si $\mathrm{x}=\mathrm{V}$ obligan o bien a rechazar la Condición de Adyacencia, solución poco apropiada en vista de los efectos que produce, o bien a suponer que se permiten reanálisis sintácticos que convierten las secuencias del tipo: ...X ...Y ...SN ...en secuencias: ... [X X $+\mathrm{Y}] \ldots[\mathrm{Y}$ e] ...SN..., en que la $\mathrm{X}$ más incluyente tiene las mismas propiedades que la $x$ que se halla en él. Hablando en términos más sencillos, la $\mathrm{X}$ que asigna marca de Caso a $\mathrm{SN}$, aunque debe estar a su lado, puede estar compuesta por una secuencia reanalizada $[\mathrm{X} X+\mathrm{Y}]$. Así, hallamos complejos verbales del tipo $[\mathrm{V} \mathrm{V}+\mathrm{SP}]$ en que el $\mathrm{V}$ más incluyente sigue siendo transitivo si lo es el $\mathrm{V}$ incluido.

El análisis de las construcciones absolutas y las que van encabezadas por un verbo del tipo encontrar, permite identificarlas como construcciones en las que se halla SN léxico en SA con marca de Caso, obtenida de un constituyente complejo $\mathrm{X}+\mathrm{A}$, en que $\mathrm{X}=\mathrm{TMP}$ o $\mathrm{V}$. Esta solución ha resultado ser eficaz para las construcciones en que A tiene complemento oracional introducido por la conjunción que.

3.1.9. Concluimos que los adjetivos tienen complemento de la categoría SN, representado por la categoría vacía en la gran mayo- 
ría de los casos. Los reflejos que hemos ido reuniendo de la presencia de SN como complemento sintáctico de A constituyen un argumento importante a favor de la hipótesis.

\subsection{La adjetivación de la cláusula relativa introducida por "que"}

3.2.0. De acuerdo con el análisis de la sección anterior, SA se compone del núcleo A seguido de SN, que es la categoría vacía en la gran mayoría de los casos.

Si el relativo que en posición indefensa es interpretado como adjetivo, no es de extrañar que se comporte conforme a la pauta usual que exhibe A, tomando como complemento la categoría vacía. Por tanto, (101) podría representar la estructura canónica de las construcciones relativas de este tipo:

(101) [SN SN [o' [COMP [SA [A que [SN $e]]][0 \ldots[\mathrm{SN} \ell] \ldots]]]]$

Por un camino distinto hemos llegado a la misma conclusión que en el apartado anterior. El análisis estructuralista que hemos expuesto en el apartado anterior puede adoptarse dentro del marco de la teoría generativista. En ésta, las cláusulas relativas introducidas por que en posición indefensa se adjetivizan mediante que, y la referencia al antecedente se establece con el pronombre relativo vacío que es el complemento sintáctico de que. Queda por determinar cómo se establece la referencia a la función sintáctica que desempeña el pronombre relativo en la cláusula relativa. Este problema se tratará en el apartado próximo.

En esta sección, veremos los problemas que suscita la supuesta adjetivación de la cláusula relativa introducida por que en posición indefensa. La conclusión será que se presentan las mismas paradojas que en el análisis estructuralista.

3.2.1. Hasta el momento nos hemos basado en la suposición de que la adjetivación de la cláusula relativa se debe explicar por el carácter adjetivo de que en posición indefensa. La adjetivación explicaría a su vez el carácter atributivo que tiene la cláusula relativa con respecto a su antecedente. Las cláusulas relativas introducidas por P + REL son también atributos del antecedente, aunque les falta un adjetivo en COMP. En el ejemplo (102)a., que tiene la estructura (102)b., el carácter atributivo de $\mathrm{O}^{\prime}$ no se debe a ningún adjetivo:

(102)a. El chico de quien hablas es vecino mío

b. [sN el chico [o' [COMP [sp de quien]] [o hablas [SP $e]]]]$ es vecino mío 
La regla de atribución ${ }^{33}$ que indica el carácter atributivo de O' con respecto al antecedente puede formularse de la siguiente manera:

(103) En el contexto $\left[\mathrm{SN} \mathrm{SN}\left[\mathrm{O}^{\prime} \ldots\right]\right], \mathrm{O}^{\prime}$ se interpreta como atributo de SN

El carácter relativo de $\mathrm{O}^{\prime}$ podría garantizarse exigiendo que COMP contenga un pronombre relativo asociado con $\mathrm{SN}$, con lo que se obtiene la formulación revisada $\left(103^{\prime}\right)$ :

$\left(103^{\prime}\right)$ En el contexto [SN SN [o' [COMP ... REL] [o ...]]], si SN puede ser asociado con REL, $\mathrm{O}^{\prime}$ es cláusula relativa con antecedente y se interpreta como el atributo de SN.

En la estructura (101), que define las cláusulas relativas introducidas por que, se puede - y se debe - aplicar $\left(103^{\prime}\right)$ de modo que $\mathrm{O}^{\prime}$ también se interprete como atributo de $\mathrm{SN}$, sin necesidad de que el núcleo de COMP, o sea el signo que, sea adjetivo. Es decir que, una vez admitida una regla de atribución como (103) o (103'), es superfluo el uso de un adjetivo para convertir la cláusula en una función adjetiva. No queremos decir con esto que sea imposible que que sea adjetivo, sino solamente que no es necesario.

3.2.2. La exposición que acabamos de concluir en la primera sección de este capítulo se ha basado en la estructura de SA; no obstante, se hallan también atributos nominales del tipo que se ejemplifica en (104):

(104)a. Presidente yo, el país se derrumbaría

b. Eligieron presidente al astronauta

No cabe duda que presidente es un nombre, aunque funciona como atributo en (104)a., b. Todos los argumentos que se han aducido para demostrar que A tiene complemento de la categoría SN son válidos para demostrar que $\mathrm{N}$ también lo tiene. Es decir que a (104)a., b. les corresponden indudablemente las estructuras que se esbozan en (105)a., b.

(105)a. [SN [N presidente] [SN yo]], el país se derrumbaría b. eligieron [SN [N presidente] [SN a Juan]]

${ }^{33}$ Esta regla se llama una regla de "predicación" en E. Williams, "Predication", $L I, 11$ (1980), 203-238; nos basamos en este análisis. Véase también, Chomsкi, "On WH-Movement". 
No cabe duda que ha sido más conveniente hablar de la estructura de SA, ya que los argumentos se aplican con más claridad a esta categoría; el uso limitado de SN con las mismas propiedades demuestra que ciertas palabras de la categoría léxica $\mathrm{N}$ se comportan como si fuesen adjetivos.

Es sorprendente el uso de $\mathrm{N}$ en (105)a., b., ya que se trata de un contexto en que $\mathrm{N}$ - presidente - no puede recibir marca de $\mathrm{Ca}$ so. Por lo visto, la marca de Caso no es necesaria para $\mathrm{N}$ léxico, si éste funciona como atributo. Se impone, pues, la condición adicional siguiente:

(106) Los SN desprovistos de marca de Caso se interpretan como atributos; de no ser posible esta interpretación, se rechazan.

En resumidas cuentas, la estructura de SA tal como ha sido tratada en el apartado anterior, también vale para SN atributivo, esto es, el SN con núcleo nominal desprovisto de marca de Caso que admite interpretación atributiva.

3.2.3. La adjetivación de la cláusula relativa introducida por que en posición indefensa consiste en que la cláusula se interpreta como atributo del antecedente. En vista de que una regla de atribución tal como (103) o (103') debe formar parte de la gramática para explicar el carácter atributivo de las cláusulas relativas introducidas por P + REL, no es necesario estipular que la atribución se debe al uso de que. Aun si el uso de que fuese el factor crucial para determinar el carácter atributivo de la cláusula relativa, que podría ser interpretado como nombre.

Como los SN atributivos parecen exhibir las mismas características que los $\mathrm{SA}$ - que siempre son atributos - se puede seguir sosteniendo que lo normal es que $\mathrm{N}$ vaya seguido de un complemento SN vacío, con lo que concluimos de nuevo que la existencia de un pronombre relativo al lado de que se ha comprobado de manera distinta que en el capítulo anterior. Nos queda por determinar la categoría de que, el Caso que recibe, y el Caso que recibe el pronombre relativo vacío.

Si que se interpreta como adjetivo, no es necesario que tenga marca de Caso. Si que se interpreta como nombre, puede tener o no tener marca de Caso, ya que podría interpretarse como nombre con valor atributivo, que determina el carácter atributivo de la cláusula relativa. El pronombre relativo vacío, a su vez, o bien se comporta de manera igual que los nombres léxicos, y entonces recibe Caso, o bien carece de él por razones que convendría des- 
cubrir. En el apartado próximo se verán las soluciones que se imponen.

\section{SiNTAXIS DE LOS PRONOMBRES RELATIVOS: ANÁLISIS GENERATIVO}

\subsection{Introducción}

En este apartado, se tratarán los aspectos más importantes de un análisis generativo de los pronombres relativos en español. El objetivo primordial será descubrir por qué los pronombres relativos se permiten sólo después de una preposición y no en posición indefensa, a no ser que falte el antecedente.

En la primera sección, veremos que la teoría de los Casos no sirve para explicar la distribución de los pronombres relativos, aunque apunte en una dirección correcta. Esto se demuestra comparando la distribución de los pronombres interrogativos y los relativos. La comparación hará ver que éstos tienen carácter anafórico y aquéllos no. Concluiremos que los pronombres anafóricos, por lo visto, están sujetos a una restricción: deben hallarse regidos. La rección es un concepto cuya definición se irá presentando poco a poco. Como la posición indefensa después de antecedente no es una posición regida, no se pueden hallar en ella los pronombres relativos con carácter anafórico.

En la segunda sección, pasaremos revista a las propiedades de los tipos de pronombres anafóricos no relativos, mostrando que el concepto de rección debe ser utilizado para poder explicar su comportamiento.

La distribución de REL y que se tratará en la tercera sección. Se verá que la nueva hipótesis permite llegar a una explicación natural de la sintaxis de los pronombres relativos y que, sin que sea necesario echar mano de hipótesis auxiliares adicionales.

\subsection{Los pronombres interrogativos y los relativos}

Las construcciones interrogativas introducidas por un constituyente interrogado tienen mucho en común con las cláusulas relativas $^{34}$. El paralelismo más obvio es que el inventario de los morfemas interrogativos es casi idéntico al de los relativos. Quien

${ }^{34} \mathrm{El}$ paralelismo ha sido subrayado siempre en los estudios generativos; véase J. SHRoten, "Two Approaches to the Distribution...", para una elaboración del razonamiento. 
interrogativo y quien relativo, qué interrogativo y que relativo son testimonio del paralelismo. Ahora bien, el contraste que hay entre (107)a. y (107)b. no tiene explicación en el sistema que hemos venido desarrollando:

(107)a. ¿Quién ha venido?

b. ${ }^{*}$ E1 chico quien ha venido

La estructura de (107)a., b. se muestra en (108):

\section{(108) [o' [COMP [SN quien]] [o [SN $e]$ INFL [sv hab-venido]] $]^{35}$}

Si quien se considera como nombre léxico, debe recibir marca de Caso, como acabamos de ver en el apartado anterior. Se observa que la posición en que se encuentra quien en (108) queda al margen de o. De hecho, se trata de una posición en que no es regido ni por INFL ni por $\mathrm{V}$ ni por $\mathrm{P}$. Por tanto, se podría achacar el rechazo de (107)b. a la falta de marca de Caso. Pero esta explicación no puede ser adecuada, ya que quién interrogativo, que se halla en la misma posición en (107)a., no se rechaza.

Obsérvese que la marca de Caso que asigna INFL —o tal vez TMP, como acabamos de ver en el apartado anterior - puede ir a parar a [SN $e]$, que se halla en la posición del sujeto, regida por INFL. Siendo [SN $e$ ] nombre no léxico, ya que carece de representación fonológica, puede pasar la marca de Caso a quién, con que

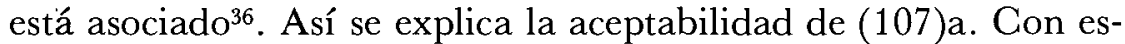
ta hipótesis, sin embargo, no se explica el rechazo de (107)b., en que se asocian quien y [ $\mathrm{SN} e]$ de la misma manera que en (107)a., de modo que quien recibe marca de Caso.

Si nos limitamos a la distribución de los pronombres relativos, el contraste entre la posición protegida y la indefensa se explica fácilmente mediante la teoría de la marca de Caso, que esbozamos en el apartado anterior. Recuérdese que P asigna marca de Caso, de modo que el pronombre relativo que sigue a $\mathrm{P}$ recibe la marca de Caso directamente de $\mathrm{P}$ en la posición protegida.

${ }^{35}$ En realidad E. Torrego, "On Inversion in Spanish and Some of Its Effects", $L I, 15$ (1984), 103-131, ha demostrado que el verbo de la oración o cláusula se halla en la posición contigua a COMP, fuera de $\mathrm{O}$, de modo que la estructura (1)a. debería representarse como (i):

(i) [O' [COMP [SN quien] [V INFL hab-venido]] [O [SN $e][\mathrm{V} e]]]$ '

Como esta diferencia no afecta al argumento, no ha sido tomada en cuenta.

${ }^{36}$ Véanse N. Ghomskr, "Remarks on Nominalization", en R. Jacobs y P. Rosenbaum (eds.), Readings in English Transformational Grammar, Blaisdell, Waltham, MA, 1970; y Lectures on Government... 
En la indefensa, no recibe marca de Caso directamente. Dado el paralelismo con los pronombres interrogativos, podemos dar por sentado que recibe la marca de Caso indirectamente, por "herencia" de la categoría vacía en 0 .

Es curioso que la teoría de la marca de Caso apunte en la dirección correcta, aunque no puede ser la solución adecuada. La solución sería adecuada si pudiéramos trazar una distinción entre la asignación directa y la indirecta de la marca de Caso a los pronombres relativos y si pudiéramos mostrar por qué no es pertinente la distinción para los pronombres interrogativos.

Ahora bien, la marca de Caso se asigna directamente por P, $\mathrm{V}$ e INFL si rigen a su complemento, mientras que la "herencia", o sea, la transmisión de la marca de Caso de un SN vacío a otro léxico no requiere que los dos SN tengan una relación de rección. Podríamos suponer, pues, que los pronombres relativos deben estar regidos y los interrogativos no. Sigue siendo verdad que los dos tipos de pronombres, si son léxicos, requieren marca de Caso, que habrán recibido directamente de un elemento que los rige o indirectamente por "herencia" de un elemento que no los rige.

Los pronombres relativos se distinguen de los interrogativos en que éstos no tienen antecedente y aquéllos sí. En este respecto, los pronombres relativos se parecen a otros pronombres que también pueden o deben tener antecedente, a saber, los personales y los reflejos que se llaman anafóricos, lo cual sugiere que los relativos también son anafóricos.

La paradoja que se nos presenta en (107)a., b. se solucionaría si pudiéramos demostrar que todos los pronombres anafóricos deben estar regidos. Se necesita, claro está, una definición exacta de lo que debemos entender por "estar regido".

De ser cierta la hipótesis, los pronombres relativos, de la misma manera que los interrogativos, siempre reciben marca de Caso, pero, a diferencia de los pronombres interrogativos, también deben estar regidos por ser pronombres anafóricos.

\subsection{La anáfora y los pronombres relativos: la condición del régimen}

4.2.0. Veamos primero cómo se realiza la propiedad de tener antecedente en los pronombres no relativos ${ }^{37}$. Consideremos al respecto el pronombre reflejo se en construcciones del tipo que se muestra en (109):

37 Presentamos algunas hipótesis propuestas en CHOMSKY, Lectures on Government..., limitándonos a los puntos de mayor pertinencia para este estudio. 
(109) Juan dice que Pedro se afeitó

El antecedente de $s e$ es Pedro, que funciona como sujeto de la cláusula en la que se encuentra el pronombre reflejo. La asociación de se con Juan, el sujeto de la cláusula superior, es imposible de realizar.

El pronombre personal lo se comporta de manera distinta, como es fácil verificar en (110):

\section{(110) Juan dice que Pedro lo afeitó}

El antecedente de $l o$, que es pronombre personal, no puede ser Pedro, sino sólo Juan; también es posible que lo refiera a otra persona, distinta de las que se designan mediante Pedro y Juan.

El pronombre reflejo se requiere como antecedente el sujeto de la oración mínima en la que se halla; el pronombre personal $l o$, en cambio, requiere que el sujeto de la oración mínima en la que se halla no se interprete como su antecedente.

Decimos que la selección del antecedente por el pronombre equivale a un ligamiento del pronombre de parte del antecedente. Son válidas, pues, las observaciones (111)a. y (111)b.:

(111)a. El pronombre reflejo debe estar ligado en la o mínima en la que se halla;

b. El pronombre personal no puede estar ligado en la o mínima en la que se halla, o sea, debe estar libre en la o mínima.

Considérese ahora (112), en que la o mínima carece de sujeto que pueda servir de antecedente del pronombre reflejo ${ }^{38}$.

(112) Se dice que no vendrá nadie

En este ejemplo, se obtiene valor referencial "arbitrario", o sea, que refiere a una persona cualquiera. Concluimos que el pronombre reflejo que no se halla ligado en o no causa la inaceptabilidad de la construcción correspondiente, sino que está sujeto a una regla interpretativa adicional del tipo (113):

(113) El pronombre reflejo obtiene el valor referencial del antecedente; faltando éste, obtiene valor referencial arbitrario.

Los pronombres personales, que deben hallarse libres en $O$ mínima, pueden estar ligados por su antecedente, si éste se halla

38 Véase J. Schroten, "Subject Deletion or...", para una extensa presentación de este tipo de construcciones. 
fuera de o mínima; de faltarles antecedente, obtienen valor referencial deíctico.

4.2.1. El dominio dentro del cual debe hallar antecedente el pronombre reflejo y dentro del cual no puede hallar antecedente el pronombre personal no es única y exclusivamente $O$, sino que ciertos tipos de SN constituyen dominios pertinentes con respecto al antecedente del pronombre.

Considérese al respecto los ejemplos (114)a., b.:

(114)a. Juan detesta la confianza de Pedro en sí mismo b. Juan detesta la confianza de Pedro en él

Se observa que sí mismo sólo puede estar ligado por Pedro, mientras que esto es imposible con él. El antecedente de él, en cambio, no puede ser Pedro, sino solamente Juan, permitiéndose también que él refiera a otra persona distinta de Juan o de Pedro.

El constituyente de Pedro se comporta, pues, como el sujeto del $\mathrm{SN}$ : la confianza, por lo que se refiere a la interpretación de los pronombres.

El mismo fenómeno se observa en (115):

(115)a. *Juan detesta mi confianza en sí mismo

b. Juan detesta mi confianza en él

El pronombre posesivo mi actúa como sujeto con respecto al ligamiento del pronombre. En (115)a., si mismo debe elegir como antecedente a $m i$, pero esto da como resultado una interpretación incoherente, por lo que se rechaza la construcción. En (115)b., él no puede coindexarse con $m i$, de modo que no puede producirse ninguna incoherencia; es posible que él refiera a Juan o a otra persona.

Hablando en términos generales, decimos que el dominio pertinente dentro del cual debe hallar antecedente el pronombre reflejo y evitarlo el pronombre personal es el constituyente léxico independiente mínimo dentro del cual se hallan un sujeto y el pronombre. A este dominio llamamos dominio de régimen ${ }^{39}$.

39 Dado el carácter limitado de los datos que hemos tenido en cuenta, la definición del concepto de "dominio de régimen" es tentativa. Se han propuesto varias definiciones en CHOMSKY (Lectures on Government...), donde se halla una exposición larga y tendida; en casi todos los estudios afines a este texto de Chomsky se proponen modificaciones, como en O. JAEGGLI, Topics in Romance Syntax, Foris, Dordrecht, 1981; H. BORER, Parametrics Variations in Clitic Constructions, tesis doctoral, Massachusetts Institute of Technology, Cambridge, 1981. 
4.2.2. Volviendo a los pronombres relativos, podemos tratarlos como morfemas ligados, al igual que el pronombre reflejo. El dominio de régimen pertinente se muestra en (116):

$$
\text { (116) }[\mathrm{SN} \text { SN [O' [COMP (P) REL] [o …...]]] }
$$

Siguiendo la pauta establecida por los pronombres reflejos y personales, observamos que SN debe ser tratado como el sujeto de la construcción. De hecho, el antecedente de la cláusula relativa funciona como un sujeto de la cláusula relativa, que es su predicado. ${ }^{40}$

Definiendo, pues, el SN antecedente como el sujeto de $\mathrm{O}^{\prime}$, que es su predicado, el dominio de régimen de los pronombres relativos es la construcción relativa entera que puede definirse de la manera siguiente:

(117) El pronombre relativo debe estar ligado en SN, puesto que es el constituyente independiente mínimo dentro del cual se halla el sujeto al que debe referir.

Adoptando esta aproximación notamos que la única diferencia entre COMP que contiene solamente REL y COMP que se compone de P + REL consiste en que REL no se halla regido.

Como ya sugeríamos antes, REL debe tener marca de Caso, al mismo tiempo que está sujeto a la condición de tener que hallarse regido. Aunque sigue siendo verdad que REL debe recibir marca de Caso, esta exigencia no es el motivo por el que se rechaza (107)b., sino que es la condición de que REL debe hallarse regido la que permite trazar la distinción pertinente. Extendiendo la condición a todos los morfemas que tienen valor anafórico, obtenemos la condición (118):

(118) Los morfemas anafóricos deben hallarse regidos ${ }^{41}$.

40 Véase E. Williams (art. cit.), para una teoría de la "predicación" -que incluye la atribución - similar a la que adoptamos en este momento.

${ }^{41}$ El concepto de rección debería, tal vez, restringirse para cubrir solamente los contextos que estamos estudiando. Sólo me interesa señalar que se trata de una condición que rige también la asignación de la marca de Caso. De ahí que la teoría del Caso apunte en la dirección correcta para poder explicar la distribución de los pronombres relativos. Una condición de rección similar explica la distribución de la categoría vacía; cf. СномSкy, Lectures on Government... 
Como los pronombres interrogativos carecen de valor anafórico, no están sujetos a la condición (118). Los pronombres relativos, en cambio, sí están sujetos a ella ${ }^{42}$.

No hemos tenido en cuenta hasta el momento las cláusulas relativas carentes de antecedente; la estructura pertinente se esboza en (119):

$$
\text { (119) }\left[\mathrm{O} \cdots\left[\mathrm{O}^{\prime}[\mathrm{COMP}(\mathrm{P}) \mathrm{REL}][\mathrm{O} \ldots e . . .]\right] \ldots\right]
$$

Éstas desempeñan función nominal en la oración matriz, hallándose regidas por INFL (si funcionan como sujeto), V (si funcionan como complemento directo) o P (si son términos de una preposición) $)^{43}$.

El concepto de rección se define de la manera siguiente:

(120) En la configuración: $[\ldots \alpha \ldots \beta \ldots], \beta$ es regido por $\alpha$ : a. si $\alpha=N, V, P, A$ O INFL

b. si el constituyente mayor -o sea SN, SV, SP, SA, o- mínimo que contiene $\beta$ contiene también $\alpha$.

En términos más correctos se definen las configuraciones que se hallan en (121) como configuraciones de régimen:

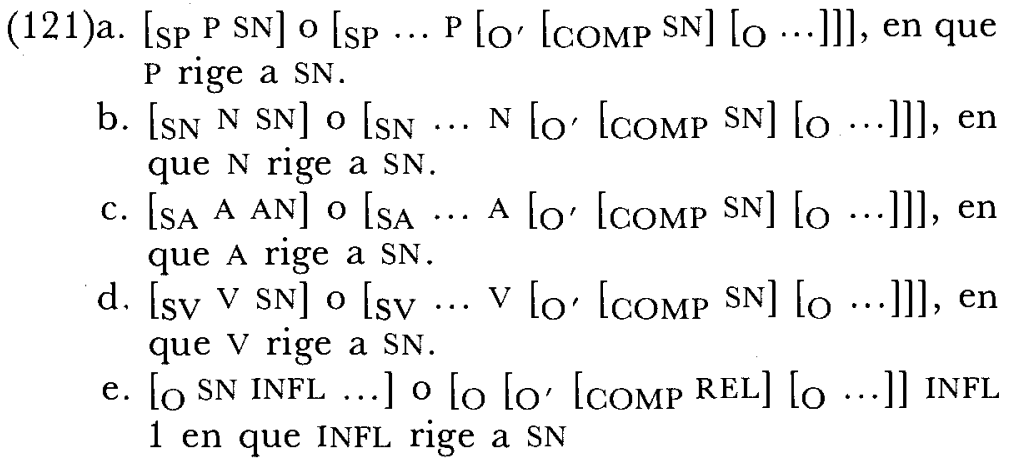

Dando por sentado que el régimen se mantiene a través de O' y COMP, hallamos que REL, en las cláusulas relativas carentes de

42 Los pronombres relativos del italiano son tratados como anafóricos en G. Cinque, "On the Theory of Relative Clauses...", donde se discuten otras propiedades.

43 Véanse S. Plann, op. cit.; M. Suñer, "Free Relatives and the pro-Head Hypothesis", Cornell Working Papers, 4 (1981); P. HirschbüHLer y M. L. RIVERO, art. cit. y "Remarks on Free Relatives and Matching Phenomena', $L I, 14$ (1983), 505-520. Una versión elaborada de mi propuesta en J. SchroTEN, "Two Approaches to the Distribution..." 
antecedente, está regido por un rector que se halla fuera de la construcción relativa.

Con esto solucionamos una paradoja que habíamos pasado por alto. Considérese la construcción ejemplificada en (122):

(122) Contamos con quien llega en este momento

Se nos impone el análisis siguiente: quien obtiene marca de Caso, ya que se asocia con la categoría vacía regida por llega (o, mejor dicho, INFL, que forma parte de llega). Al mismo tiempo, la preposición con, que depende del verbo de la oración matriz, rige a quien a través de $\mathrm{O}^{\prime}$ y COMP, de modo que quedan satisfechas las dos condiciones a que está sujeto quien. Este morfema léxico y anafórico tiene marca de Caso y se halla regido, aunque no recibe marca de Caso de su rector ${ }^{44}$.

Respecto a la interpretación de quien, la falta del antecedente hace que se interprete como refiriendo a una persona "arbitraria" (o sea, que no necesariamente se puede identificar referencialmente), por lo que se comporta igual que el pronombre reflejo se, cuando éste se usa en sentido impersonal.

La interpretación "arbitraria" o "de persona arbitraria" es bastante obvia en el ejemplo siguiente:

(123) Quien mal anda mal acaba.

4.2.3. Los pronombres relativos se comportan como el pronombre anafórico se en que deben hallar "sujeto" en el dominio de rección. De faltarles "sujeto", obtienen interpretación arbitraria.

Como los pronombres relativos parecen estar sujetos a la condición de la rección (118), cabe investigar si el pronombre reflejo se también obedece a una condición similar, tal como ha sido formulada en (118). El concepto de rección que ha resultado ser pertinente en el caso de los pronombres relativos puede definirse de la manera que mostramos en $(124)^{45}$ :

(124) REL está regido en los contextos siguientes:

a. [SP P REL]

b. $\left[\mathrm{SV} \ldots \mathrm{V}\left[\mathrm{O}^{\prime}[\mathrm{COMP} \mathrm{REL}] \ldots\right] \ldots\right]$

\footnotetext{
${ }^{44}$ Si quien recibiese marca de Caso de con, tendría Caso oblicuo, aunque se asocia con una categoría vacía con Caso nominativo. De acuerdo con la hipótesis actual, quien tiene Caso nominativo, por "herencia", hallándose regido por con. Véase también Schroten, "Two Approaches to the Distribution..."

${ }^{45}$ La definición limitada (124) sólo sirve para hacer más concreta la exposición; la definición general (118) sigue siendo válida.
} 


$$
\begin{aligned}
& \text { c. }\left[\mathrm{SP} \ldots \mathrm{P}\left[\mathrm{O}^{\prime}[\mathrm{COMP} \text { REL }] \ldots\right] \ldots\right] \\
& \text { d. }\left[\mathrm{O}\left[\mathrm{O}^{\prime}[\mathrm{COMP} \text { REL }][\mathrm{O} \ldots]\right] \text { INFL } \ldots . .\right]
\end{aligned}
$$

De manera más abstracta obtenemos la definición (125):

(125) $\beta$ se halla regido por $\alpha$

a. si $\alpha=$ P, V, INFL, $y$

b. si $\alpha \beta$ o $\beta \alpha$ se hallan en el mismo constituyente $\alpha^{\prime}$.

El pronombre reflejo se forma parte de un complejo verbal, abreviado $\mathrm{CV}$, compuesto por uno o más pronombres átonos (entre los cuales se halla $s e)$ y $\mathrm{V}$.

$$
\text { (126) [sv [ CV se... V] ...] }
$$

La definición más abstracta (125) podría interpretarse de tal manera que se esté regido por $\mathrm{V}$, puesto que $\mathrm{CV}=\mathrm{V}^{\prime}$. Con esto se comprobaría la condición más general (118).

Se nos presentan algunas dudas con esta interpretación. Por lo general, los constituyentes de la categoría $\mathrm{X}^{\prime}$ o a' no pueden funcionar como rectores a su vez. Se seguiría que los complejos verbales compuestos por un pronombre átono y un verbo no pueden actuar como rectores, conclusión obviamente falsa en vista de la aceptabilidad de (127):

(127) Juan te enseñó lo que debías coger

El pronombre relativo debe hallarse regido por el verbo en la oración matriz, lo que hace imposible analizar el complejo verbal te + enseñó como un constituyente de la categoría $\mathrm{V}^{\prime}$. Debemos estipular, pues, que el complejo verbal se comporta ambiguamente: en el interior $\mathrm{V}$ actúa como rector respecto al pronombre átono, mientras que el complejo verbal entero se comporta como un verbo "sencillo", sirviendo de rector con respecto a lo que.

El dominio de régimen de REL es SN - si hay antecedente$\mathrm{u} \mathrm{O}^{\prime}$ - si no lo hay. El dominio de régimen de se es $\mathrm{O}$, si hay sujeto, o SV, si no lo hay. El rector normalmente se halla dentro del dominio de régimen, pero los pronombres relativos que carecen de antecedente encuentran rector fuera de este dominio.

En términos generales, el concepto de dominio de régimen se puede definir de la manera que mostramos en (128):

(128) El dominio de régimen de un morfema se compone del predicado mínimo en que se halla, más su sujeto si lo hay.

El predicado mínimo de los morfemas que se hallan en SV es SV; los morfemas que se hallan en COMP tienen como predicado mínimo el constituyente $\mathrm{O}^{\prime}$. 
Con esta definición no se sabe si los morfemas que se hallan en la posición del sujeto tienen dominio de rección o no. Se impersonal supuestamente está regido por SV, que es su dominio de rección ${ }^{46}$; obtiene interpretación arbitraria, ya que le falta el sujeto. Hay más: se impersonal actúa como sujeto, de modo que la "persona arbitraria" a que refiere se interpreta como un sujeto léxico. Esto sugiere que hay una doble interpretación del sv que contiene se impersonal, según la cual la secuencia [sv se ... V ...] se interpreta al mismo tiempo como se sujetó más el predicado [Sv ... V ...]. Otro tanto se observa con los pronombres relativos que carecen de antecedente, puesto que el valor "arbitrario" que obtienen se asignas al mismo pronombre relativo. En este caso, se analiza la secuencia: [O' REL [O]] como sujeto REL más predicado o. El doble análisis se detalla en (129):

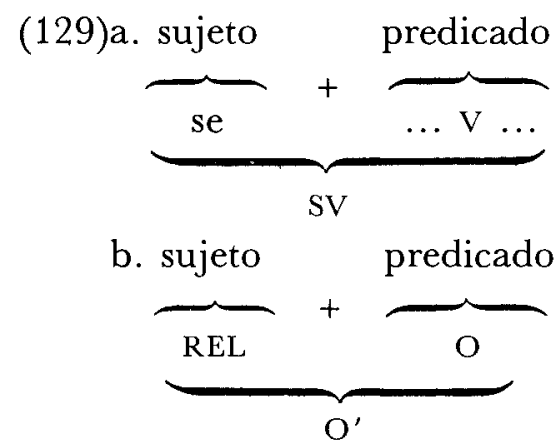

Este doble análisis permite aclarar el concepto de dominio de rección, teniendo en cuenta que el sujeto que falta se suple mediante un análisis que se efectúa en otro nivel, el de la predicación. Si se permite este recurso analítico, obtenemos la definición (130):

(130) El dominio de rección de un morfema se compone del constituyente mínimo que lo contenga y que se pueda analizar como una estructura con sujeto y predicado.

4.2.4. El carácter anafórico de los pronombres relativos se puede comprobar estudiando las dos condiciones a las que parecen estar sujetos tanto los pronombres relativos como el pronombre reflejo se.

46 Puede suponerse también que se impersonal forma parte de INFL, haciendo las veces de AGR. La interpretación correspondiente sería que se se halla regido por TMP, actuando como sujeto implícito, que también actúa como sujeto; cf. J. Schroten, "Subject Deletion or..." 
La condición de rección de REL parece aplicarse también a se, aunque este morfema tiene una distribución más limitada. La condición de que el pronombre reflejo se debe hallar sujeto en su dominio de rección se aplica también a REL, una vez que se extiende el concepto de dominio de rección.

Es, sobre todo, el paralelismo entre se impersonal y los pronombres relativos que carecen de antecedente lo que permite afirmar que la aparente idiosincracia de REL se debe a su anaforicidad.

\subsection{La distribución de que y REL}

4.3.0. Como es inadecuada la hipótesis de que REL no recibe marca de Caso si no va precedido de $P$, puesto que siempre la recibe por "herencia", conviene revisar nuestra interpretación de que relativo. Este morfema se halla en los contextos en que no se admite REL. Hemos comprobado que REL no se admite en posición indefensa por ser pronombre anafórico que debe estar regido. Se sigue que que relativo no es pronombre anafórico y que no debe estar regido. De nuevo cabe preguntarse si que puede ser un nombre, en cuyo caso sólo se distinguiría de REL por el carácter no anafórico.

4.3.1. Considérense los ejemplos siguientes:

(131)a. *E1 chico [o' quien [o $e$ ha venido]]

b. El chico [O' que [o $e$ ha venido]]

En (131)a., quien recibe Caso nominativo por su asociación con la categoría vacía en posición del sujeto simbolizada por $e$. Este Caso se transmite de $e$ a quien. El rechazo de quien no tiene que ver con la falta de marca de Caso, sino que se debe a la falta de un rector apropiado. En (131)b., e recibe marca de Caso. La cuestión es saber si lo transmite a que.

La falta de anaforicidad que debemos suponer como característica de que relativo lo hace incapaz de funcionar como pronombre relativo. En dos ocasiones hemos tenido ocasión de ver que que relativo va acompañado de un pronombre relativo desprovisto de contenido fonológico. La transmisión del Caso nominativo a partir de la categoría vacía en o se efectúa, pues, en REL vacío, lo que presupone la estructura (132):

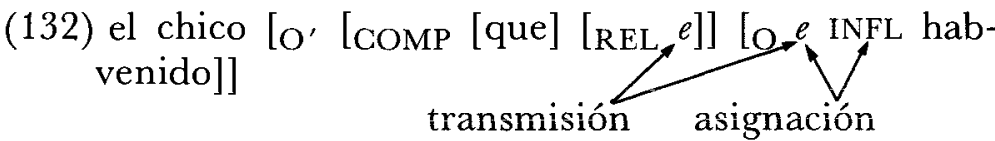


Por lo visto, que no recibe marca de Caso, lo que llevaría a suponer que no puede ser nombre.

Ahora bien, considérese el ejemplo (133)a. y su estructura (133)b.:

(133)a. ${ }^{*} \mathrm{E} 1$ chico que quien ha venido

b. El chico [o' [COMP [que] [quien] [o $e$ INFL habvenido]]

El rechazo del ejemplo, a primera vista, no tiene explicación evidente: quien tiene marca de Caso, que le es transmitida por $e$; que puede considerarse como su rector, dada la definición original del concepto de rección, tal como se ha formulado en (121). Sólo se explica el rechazo de (133)a., si que es analizado como nombre; aunque quien recibe marca de Caso, no la recibe que, razón por la cual (133)a. no se admite ${ }^{47}$. Nos queda por determinar si que obtiene Caso en (132). La hipótesis auxiliar que se impone es que el Caso de REL vacío se combina con que o sea, que que recibe el Caso de su complemento vacío. Con esta hipótesis auxiliar, que se presenta en (134), el paradigma de que tiene explicación plausible:

$$
\text { QUE }[\text { REL CASO }] \Rightarrow[\underset{\text { CASO }}{\text { QUE }}]
$$

De hecho, se podría estipular simplemente que los rasgos gramaticales (que incluyen marca de Caso) del complemento vacío de que pasan a formar parte de $q u e^{48}$. De esta manera podemos trazar una distinción entre que completivo (desprovisto de índice referido a una categoría vacía en o) y que relativo, que sí tiene índice. (135)?

¿Qué pasa si [REL $e]$ no se halla acompañado de que, como en

(135)a. * E1 chico ha venido es mi vecino

b. El chico [o' [COMP [ReL $e$ ]] [o $e$ INFL hab- venido]] es mi vecino

47 Téngase en cuenta que la secuencia que quién es aceptable en:

(i) Preguntó que quién había venido

En este ejemplo, que obtiene Caso de preguntó, mientras que quién obtiene Caso nominativo por herencia. No hay, pues, ninguna restricción general que prohiba la secuencia: que quién.

${ }^{48}$ Una fusión similar ha sido propuesta por CHOMSKy ("On WHMovement'”) con respecto a that relativo en inglés. 
Se observa que REL no tiene rector, razón por la que se excluye esta construcción con REL vacío no acompañado de que. Con esto damos a entender que, en la configuración [que] [REL $e$ ], que actúa como rector de REL, mientras que este constituyente transmite su marca de Caso a que, salvándolo del rechazo. En esta interpretación revisada, pues, que relativo se interpreta como un nombre, que es rector del pronombre relativo vacío que le "entrega', la marca de Caso.

4.3.2. La distribución de que y REL puede explicarse de la manera siguiente. Tanto que como REL son nombres que requieren marca de Caso. A diferencia de REL, que no tiene valor anafórico, por lo que se sustrae a la condición de régimen a lo que están sujetos todos los pronombres anafóricos. Que actúa como rector de REL vacío, y recibe de él marca de Caso. REL léxico, en cambio, necesita la marca de Caso y no la puede transmitir, de modo que se excluye la secuencia que + REL léxico.

\subsection{Resumen}

La sintaxis de los pronombres relativos en español se puede resumir de la manera siguiente. Los signos pertinentes son: el que, el cual, que son pronombres relativos sin rasgo inherente [土humano], por lo que pueden referir a cualquier tipo de antecedente. Quien y que son también pronombres relativos léxicos, con el rasgo inherente [ + humano] y [- humano], respectivamente ${ }^{49}$.

Como se trata de nombres no vacíos, requieren marca de $\mathrm{Ca}$ so. Además, están sujetos a la condición de régimen por ser pronombres anafóricos.

El pronombre relativo vacío [REL $e$ ] recibe marca de Caso por herencia y está sujeto a la condición de rección por el pronombre anafórico. $\mathrm{Al}$ ser nombre fonológicamente nulo, no necesita la marca de Caso, que va a parar a que relativo en posición indefensa.

El complementador que es nombre gramatical desprovisto de valor anafórico. Al ser nombre no vacío requiere marca de Caso, que le es asignada por [REL $\ell$ ] en las construcciones relativas.

${ }^{49}$ Que como REL léxico prefiere antecedente no humano; sin embargo, no rechaza los antecedentes humanos. Véase al respecto el ejemplo (37) del segundo apartado de este trabajo. Por consiguiente, la caracterización de que como [-humano] no puede ser correcta. No tengo solución adecuada; véase también nota 13. 
5. Comparación dE los ANÁlisis: ESTRUCTURALISMO Y GENERATIVISMO

\subsection{Introducción}

En este capítulo final me propongo examinar las diferencias entre el tratamiento estructural y el generativo de las cláusulas relativas en español. Intentaré comprobar si las diferencias se siguen de los distintos puntos de vista metodológicos y epistemológicos que caracterizan los dos marcos teóricos.

La escasez de estudios basados en el estructuralismo frente a la abundancia de estudios inspirados por el generativismo se refleja en la composición de los apartados precedentes, en que hemos dedicado mucha menos atención al tratamiento estructural que al generativo. No hemos podido evitar tampoco que el análisis estructural tenga un carácter muy global, que lo distingue netamente del tratamiento pormenorizado usual en los estudios generativos. La diferencia cuantitativa debe ser considerada como accidental, aunque no puede dejar de tener efectos en la calidad de los análisis que se han propuesto; no insistiremos en ella.

El foco de interés del análisis estructural ha sido la adjetivación de la cláusula relativa, mientras que el tema más importante del análisis generativo ha consistido en explicar la ausencia de los pronombres relativos de la posición indefensa. Esta distinta apreciación de lo que constituye la propiedad más interesante de las cláusulas relativas se tratará en la primera sección de este apartado final.

En la segunda, mostraremos que, en el plano metodológico, se acepta un principio de "simplicidad" en las dos teorías; la aplicación del principio arroja resultados muy distintos, debido a que se definen distintos objetivos teóricos.

En la tercera, hablaremos del funcionalismo que caracteriza los desarrollos recientes del estructuralismo y el generativismo, mostrando que este concepto tiene interpretación totalmente distinta en las dos teorías.

La sección final estará dedicada a resumir el contenido de este apartado; acabará con algunas conclusiones generales.

5.1. La adjetivación de las cláusulas relativas y la ausencia de los pronombres relativos de la posición indefensa

5.1.0. En el análisis estructural, la transposición de la cláusula a la función adjetiva constituye la característica fundamental de las cláusulas relativas. Al mismo tiempo, el uso de que relativo sirve 
para señalar "funciones cumplidas ordinariamente por sintagmas nominales a que hace referencia" ${ }^{50}$. La relativización consiste en la "refundición de dos posibles oraciones, con términos comunes, a una sola" (ibid., p. 197). El término común es el antecedente de la cláusula relativa, de modo que la relativización se interpreta de la manera que se esboza en (136):

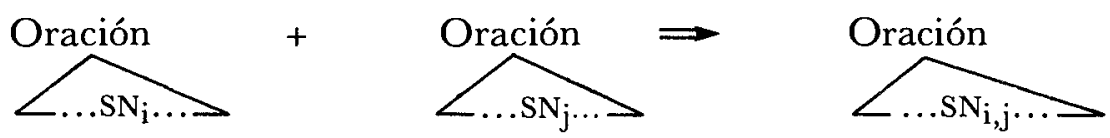

Los índices $i, j$ refieren a funciones sintácticas o indicios funcionales. La secuencia que se compone del antecedente y el constituyente relativizado en COMP - hablando en terminología generativa- se analiza, pues, como un solo SN con dos indicios funcionales. De hecho, podríamos estipular que el indicio funcional $(P, a, \varnothing)$, que acompaña al pronombre relativo, forma parte del antecedente; el pronombre relativo, según esta hipótesis, sirve solamente para transponer la cláusula a la función adjetiva. Un ejemplo tal como (137)a. se analiza, pues, de la manera que se ve en (137)b.:

(137)a. No conozco al chico de que hablas

b. No conozco $[F(i)$ a $]+[S N$ el chico $]+[F(j)$ de $]$ [A que hablas]

$\mathrm{El}$ indicio funcional $\mathrm{F}(\mathrm{i})=a$ refiere a la función que el chico cumple en la oración principal, mientras que el indicio funcional $\mathrm{F}(\mathrm{j})=$ de refiere a la función que este mismo SN cumple en la cláusula relativa. El signo que es transpositor de una cláusula a la función adjetiva. La interpretación que ofrecemos aquí evita la paradoja que habíamos observado en el apartado 2, paradoja consistente en que de acompañaba a que, el transpositor a la función adjetiva, aunque de, si sirve de indicio funcional, normalmente acompaña a un SN.

No obstante, el uso de quien en un ejemplo tal como (138) no tiene explicación:

(138) No conozco al chico de quien hablas

Si suponemos que quien transpone la cláusula a la función adjetiva, no podemos dar cuenta de su uso en las cláusulas relativas que carecen de antecedente, en las que quien sirve para transponer la cláusula a la función sustantiva. La ausencia de quien de

${ }^{50}$ Alarcos, op. cit., p. 196. 
la posición indefensa sugiere que es la preposición de la que transpone la cláusula a la función adjetiva. De hecho, debemos suponer que la cláusula cumple función sustantiva por el uso de quien, de modo que $d e$ sirve para transponer la función sustantiva quien hablas a la adjetiva de quien hablas. Al mismo tiempo, de es indicio funcional asociado con el chico, refiriendo a la función que cumple este SN en la cláusula hablas.

La paradoja se podría salvar suponiendo que la transposición de la cláusula a la función adjetiva se efectúa mediante un transpositor "cero" ( $\varnothing$ ) en todos los casos, de modo que (137)a. y (138) tienen el análisis siguiente:

(139) No conozco al chico [ $\mathrm{T}(\varnothing)$ de \{que/quien\} hablas]

Con esta hipótesis entramos en la problemática generativa de que la alternancia que / quien no es libre, ya que quien no se admite en la posición indefensa. Además, si la transposición se interpreta como un proceso realizado por un morfema de forma cero, el constituyente relativizado pertenece de lleno a la cláusula subordinada. Es necesario, por consiguiente, explicar por qué este constituyente se halla en la posición inicial, y por qué se observa la distribución que hemos observado.

De hecho, en el análisis generativo se da por sentado que a la cláusula se le asigna función atributiva o "predicativa", sea mediante una regla "de predicación" según la cual la secuencia $\mathrm{SN}+\mathrm{O}^{\prime}$ se interpreta como sujeto + predicado, sea mediante un "operador relativo" de forma cero que tiene los mismos efectos ${ }^{51}$. El problema que ha captado la atención no ha sido el carácter atributivo de la cláusula relativa, sino su composición interna por lo que se refiere a la distribución y posición de los pronombres relativos. La mucha atención que se da en la investigación estructural a la transposición de la cláusula relativa y la poca atención que ha sido dedicada a la distribución y posición de los pronombres relativos no se debe a razones de (in)compatibilidad, ya que los dos temas podrían y deberían ser tratados con igual atención en este marco teórico. No podemos suponer tampoco que la teoría estructural sea incapaz de incorporar modelos específicos que permitan una explicación detallada de la distribución y posición de los pronombres relativos. Más en concreto, sostenemos

51 Véase Chomsky, "On WH-Movement"; y Some Concepts and Consequen. ces of... En este último, sostiene que la cláusula relativa se introduce por un "operador cero" que liga a la categoría vacía en o, obteniéndose efectos similares a los que produce la supuesta regla de predicación. 
que no hay ningún principio estructural que prohiba la incorporación de la teoría de los Casos, o la condición de rección o la estipulación de un constituyente de la categoría COMP al comienzo de la cláusula ${ }^{52}$.

Respecto a la teoría generativa, hemos tenido ocasión de ver que el concepto de adjetivación no es incompatible con ella, a pesar de que se haya impuesto la conclusión de que el signo que no sirve de transpositor a la función adjetiva. Las razones que nos han llevado a sacar esta conclusión han sido empíricas; no hay ningún principio generativo que pueda ser invocado para rechazar de antemano el tratamiento estructural que ha puesto Emilio Alarcos ${ }^{53}$.

En resumidas cuentas, las hipótesis específicas de una y otra teoría han resultado ser compatibles con los dos marcos teóricos; no hay ninguna hipótesis que pueda ser descartada por motivos de incompatibilidad en ninguna de las dos teorías.

5.1.1. El concepto de la adjetivación de la cláusula relativa, aunque es compatible con el marco estructural y con el marco generativo, recibe interpretación distinta en cada uno.

En la teoría generativa, el carácter atributivo de la cláusula relativa se interpreta como una intuición primaria con que se describen ciertas propiedades de la misma, tales como su posición con respecto al antecedente, el uso de una clase de signos llamados pronombres relativos, etc. La hipótesis de la adjetivación se considera como una manera de poder captar las propiedades que se observan. En la medida en que éstas se sigan de la hipótesis, se la tratará como empíricamente fundada.

No obstante, el concepto de atribución no tiene status privilegiado, puesto que se considera posible que designe una serie de fenómenos no homogéneos, o que, en el caso de las cláusulas relativas, no signifique más que el uso de un morfema de cierta clase o de un tema nominal que dos constituyentes tienen en

52 Su incorporación modificará el modelo actual, evidentemente; las modificaciones que han propuesto estructuralistas tales como Rojo, Gutiérrez, Alarcos, Mahmoudian y otros tienen repercusiones más graves, sin que esto signifique incompatividad con el marco estructural.

${ }^{53}$ Bastaría con estipular que el transpositor que, de la categoría adjetiva, es el núcleo de la cláusula relativa. Podría invocarse también una categoría similar a la de la formación de palabras, tal como ha sido definida por Aronoff, Siegel, Marantz y otros. 
común ${ }^{54}$. Queda por determinar, pues, si los fenómenos como el uso de los pronombres relativos pueden ser explicados o no de tal manera que el concepto de atribución sea superfluo o constituya una designación de la interacción de reglas distintas, que tienen explicación independiente, obviando la necesidad de "explicar" la atribución. Por ejemplo, el carácter atributivo de las cláusulas relativas podría ser consecuencia del uso de morfemas con valor anafórico, mientras que la sintaxis de los pronombres relativos podría ser consecuencia de las propiedades de COMP55. De hecho, el mismo concepto de "cláusula relativa" puede ser interpretado como un término descriptivo para designar los efectos de varios subsistemas independientes ${ }^{56}$. Sea como fuere, el estudio del carácter atributivo de las cláusulas relativas no sólo consiste en detectar cómo se efectúa la atribución, sino que se investiga al mismo tiempo si conviene o no distinguir una clase de cláusulas relativas y caracterizarlas como atributivas. Se someten a investigación los mismos conceptos de "cláusula relativa" y de "atribución".

En la teoría estructural, el concepto de adjetivación se incluye en una teoría del signo lingüístico ${ }^{57}$. Al definirse el signo lingüístico como la unión constante de un significante y un significado, la adjetivación de las cláusulas relativas se interpreta como el uso de cierto signo con el significado "transpositor de una función verbal a la adjetiva". Se requiere la determinación del significante correspondiente. La supuesta adjetivación de las cláusulas relativas es, por tanto, de interés fundamental para poder investigar un tipo de signo poco usual; evidentemente, se puede estipular un significante "cero" con significado de transpositor, con lo que tenemos siempre una solución a mano.

El signo lingüístico más asequible a la investigación es el lexe$\mathrm{ma}$, la palabra léxica que tiene forma fonológica (el significante) y contenido semántico (el significado). Los lexemas se dividen en clases léxicas.

¿Qué entendemos por la pertenencia de un lexema a una de-

${ }^{54}$ Véase al respecto, CHOMSKy, "On WH-Movement"; Lectures on Government...; y Some Concepts and Consequences of... en los que trata la "aboutness relation'.

${ }^{55}$ Es la hipótesis que ha sido defendida en N. Chomsky y H. LaSnik, "Filters and Control", LI, 8 (1977), 425-504.

${ }^{56}$ Es la interpretación que se defiende explícitamente en Cномsкy, Lectures on Government..

57 De ahí viene la insistencia en que la lingüística sea parte de la semióti$\mathrm{ca}$, el estudio de los signos tanto ligüísticos como no lingǘsticos. 
terminada clase léxica? El lexema mesa, por ejemplo, es un sustantivo, por lo que es capaz de funcionar como el núcleo de un constituyente con función nominal. El ser sustantivo es propiedad inherente, que podemos representar asignando a mesa el rasgo inherente $[+\mathrm{N}]$.

Se presenta el problema de saber si $[+\mathrm{N}]$ forma parte del significante o del significado o si se trata de un signo. Si forma parte del significante, no pertenece al significante fonológico sino a un sistema distinto: el significante sintáctico ${ }^{58}$; si forma parte del significado, no es comparable con lo que entendemos usualmente por significado, de modo que se trata de un subsistema independiente en el significado.

La interpretación de $[+\mathrm{N}]$ como un signo lingüístico requiere la identificación de un significante y un significado. Como la categoría léxica de un lexema determina la función sintáctica que puede desempeñar, vale más buscar cómo se debe interpretar la función sintáctica ${ }^{59}$. Limitándonos a las funciones tales como el sujeto, el complemento directo, etc., o sea, las funciones nominales, se nos presentan distintos enfoques en el marco del estructuralismo. Martinet sostiene que los lexemas (o monemas en su terminología) no tienen función sino que la asumen, por su pertenencia a cierta clase funcional, en un contexto determinado. El rasgo inherente $[+\mathrm{N}$ ], por consiguiente, es tratado como un significante con significado "función nominal". Rojo, en cambio, sostiene que hay funciones en la forma del significante, que son el sujeto, etc., y funciones en la forma del significado, tal como "agente", etc. La existencia de una clase de "transpositores" sólo tiene sentido si opera sobre un signo, cambiando su significante y significado; es inconcebible que los transpositores se limiten a cambiar solamente el significante, o el significado.

Dada la existencia de un signo como que, que convierte la función verbal en adjetiva, debemos asumir que un concepto como "clase léxica verbal" es un signo. El uso del signo que no convierte el verbo en adjetivo, sino que se crea una función más incluyente compuesta por que y el constituyente cuyo núcleo es un verbo; esta función más incluyente tiene como núcleo el signo que. La transposición consiste, pues, en el uso de que y un constituyente con núcleo verbal en una construcción más global con núcleo que

${ }^{58}$ Una propuesta similar se halla en G. Rojo, "La función sintáctica como forma del significante", Verba, 6 (1979), 107-151.

59 Véanse A. Martinet, Éléments de linguistique générale, P.U.F., Paris, 1960; G. Rojo, Aspectos básicos de sintaxis funcional, Ágora, Málaga, 1983. 
y función adjetiva. Se sigue de esto que el signo que tiene rasgo sintáctico [ + A] con la "función adjetiva", o sea, que el signo que tiene significante $[+\mathrm{A}]$ y significado "función adjetiva".

Con esto se definen dos problemas distintos. En primer lugar, el signo que se compone del significante [ + A] y el significado "función adjetiva" forma parte de todos los adjetivos; éstos constituirán, por consiguiente, un solo signo. Para poder distinguirlo de los signos usuales llamados lexemas o morfemas, que tienen significante fonológico, convendrían definir una nueva clase de signos llamados clasemas. Los clasemas tendrían significante no fonológico, sino puramente gramatical y significado funcional o relacional; o sea, el significado consiste en los valores que asumen en un contexto de acuerdo con las relaciones que exhiben. En segundo lugar, los signos que así se definen no son independientes, aunque convendría considerarlos como los núcleos de la construcción. Si la secuencia que + cláusula se comporta como un adjetivo, y tiene función adjetiva, se debe considerar que como el núcleo de la secuencia. Esto va en contra de la hipótesis de que los núcleos pueden funcionar siempre como signos autónomos en el discurso ${ }^{60}$.

El tratamiento de la relativización como transposición de la función verbal a la adjetiva mediante el signo que u otros que se le parecen tiene repercusiones notables en la discusión sobre qué debe entenderse por signo lingüístico. La investigación de las propiedades del signo lingüústico es el centro de gravedad de la teoría estructural. En resumidas cuentas, la supuesta adjetivación de las cláusulas relativas está relacionada con la investigación de las características del signo lingüístico, preocupación fundamental del estructuralismo. De ahí que este aspecto haya constituido el foco de interés de los estructuralistas. Los generativistas, en cambio, no le confieren ninguna posición privilegiada, ya que se trata de una mera hipótesis de trabajo que no afecta ningún punto central de la teoría.

5.1.2. La distribución de los pronombres relativos y, sobre todo, su ausencia de la posición indefensa (con excepción de que), no

${ }^{60}$ Este tipo de razonamiento no se halla en los estudios estructurales que he consultado; no obstante, permite comprender las preocupaciones que detectan en ellos. Véanse los trabajos de ALARcos, op. cit.; Gramática estructural, Gredos, Madrid, 1951; "Metodología estructural y funcional en lingüística", $R E L, 7(1977), 1-16$; “Unité distinctives et unités distinctes", $L a$ Linguistique, 14 (1978), 39-53; M. MAHMOUdIAN, Pour enseigner le français, P.U.F., Paris, s. a.; MarTinet, op. cit.; art. cit.; Rojo, op. cit.; art. cit. 
ha sido tema de investigación predilecto entre los estructuralistas. Esto se debe a que su estudio no arrojará nueva luz sobre qué debe entenderse por signo lingüístico. La ausencia de los pronombres relativos de la posición indefensa no pueden considerarse como propiedad de los signos que pertenecen a la clase de los pronombres relativos, sino que, en todo caso, constituye un fenómeno de interés para el estudio de la transposición. Se interpreta, pues, como un fenómeno secundario, cuya explicación debería hallarse en una teoría adecuada de la transposición.

La situación es distinta en la tradición generativa, en que la ausencia de los pronombres relativos de la posición indefensa constituye uno de los fenómenos más interesantes desde un punto de vista teórico.

El interés se debe a los esfuerzos generativos por construir un modelo lingüístico que explique la manera como los niños aprenden su lengua materna ${ }^{61}$. Los datos lingüísticos en los que se basa el niño son compatibles con una gran variedad de modelos gramaticales, pero no son lo suficientemente explícitos, detallados y sistemáticos para permitirle elegir el modelo adecuado de entre los teóricamente posibles con métodos esencialmente deductivos. Esto se ve claramente si se trata de datos "negativos", o sea, de construcciones agramaticales. El lingüista puede descubrir qué construcciones son agramaticales mediante pruebas empíricas sistemáticas; el niño, en cambio, no dispone de una nómina de construcciones agramaticales, ya que el no haber encontrado una determinada construcción entre las que ha oído puede ser accidental. No es plausible suponer que la ausencia de los pronombres relativos de la posición indefensa constituya un dato perceptible para el niño. De esto se sigue que las "ausencias" son el resultado del análisis que adopta el niño, y no su causa. La cuestión primordial es saber qué propiedades de los pronombres relativos le permiten concluir que su uso en posición indefensa es intolerable. Este tipo de datos "negativos" constituyen, por consiguiente, la piedra de toque de los modelos que se someten a investigación. En la medida en que los datos "negativos" sean deducibles de un modelo determinado, éste se considerará como

${ }^{61}$ Esto ha sido preocupación constante en las investigaciones generativas tratada en muchos trabajos. La exposición más clara del tema se halla en CHomsky, Aspects of the Theory of Syntax, MIT Press, Cambridge, 1965; "Remarks on Nominalization"; véase también K. Wexler, y P. Culicover, Formal. Principles of Language Acquisition, MIT Press, Cambridge, 1980. 
más adecuado, ya que el modelo permite sacar las mismas conclusiones que saca el niño.

Otro tema predilecto de investigación lo constituye el estudio de la categoría vacía, ya que ésta no puede ser interpretada como un dato que permita al niño construir su gramática, sino que su existencia sólo se interpreta como el resultado de una gramática determinada, construida sobre la base de datos "visibles"'62.

5.1.3. La diferente apreciación de la importancia que revisten dos fenómenos relacionados con el uso de las cláusulas relativas es consecuencia de los distintos objetivos primordiales que persiguen el estructuralismo y el generativismo.

En el marco de la teoría estructural es fundamental la investigación de qué debe entenderse por signo lingüístico, o sea, qué propiedades tiene el signo lingüístico. Dado el carácter enigmático del signo que, conviene someter a una investigación detallada la asociación en él de un significante y un significado. La hipótesis de la transposición categorial permite obtener una interpretación coherente de las propiedades del signo que. La insistencia en la supuesta adjetivación de la cláusula relativa tiene relación directa y justificación completa en el marco del estructuralismo. En el marco de la teoría generativa es fundamental la investigación de las gramáticas de que disponen los hablantes. Estas gramáticas se construyen sobre la base de los datos que toman en consideración al aprender su lengua materna. Los datos "negativos", tales como la ausencia de un signo de cierta posición o la existencia de la categoría vacía, no se cuentan entre los datos que sirven para la construcción de la gramática, sino que son el efecto de la composición de una gramática determinada. Los datos "negativos" deben constituir un tema de investigación importante, ya que permiten comprobar la adecuación de los modelos que construyen los lingüistas. Los modelos adecuados se distinguen de los ineficaces en que permiten deducir los datos "negativos" como resultado de las propiedades que se han descubierto en los datos positivos. La insistencia en la ausencia de los pronombres relativos de la posición indefensa se muestra plenamente justificada, si tenemos en cuenta las preocupaciones fundamentales de la teoría generativa. Concluimos que los objetivos distintos que persi-

62 Véanse ChOmsky, Lectures on Government..., y sobre todo D. BOUCHARD, On the Content of Empty Categories, tesis doctoral, Massachusetts Institute of Technology, Cambridge, 1981. 
guen el estructuralismo y el generativismo justifican la distinta apreciación de la importancia de estos dos fenómenos lingüísticos.

\subsection{El criterio de la "simplicidad" en el estructuralismo y el generativismo}

5.2.0. No escapa a nadie que las hipótesis propuestas por los estructuralistas tienen una estructura menos complicada que las que defienden los generativistas. Los capítulos precedentes son testimonio de ello. El criterio de la "simplicidad" se acepta en las dos teorías, entendiéndose que de las hipótesis descriptivamente válidas se debe preferir la más simple. La mayor complejidad de las hipótesis enmarcadas en la teoría generativa podría ser tomada como su punto débil; de hecho, los estructuralistas tienden a tildarlas de excesivamente complicadas ${ }^{63}$. Mostraremos en este capítulo que el criterio de "simplicidad" tiene distinta interpretación en los dos marcos teóricos.

5.2.1. La simplicidad que buscan los estructuralistas no se discute explícitamente; se trata de un criterio implícito que guía sus esfuerzos $^{64}$. Intentaré definirlo, siguiendo los pasos que han dado. En su estudio sobre "Español /que/", Emilio Alarcos insiste en que es necesario distinguir los datos pertinentes de los no pertinentes desde el punto de vista estructural. Se trata, pues, de descartar los datos cuya explicación no puede dar la teoría lingüística. El problema estriba en entender cómo se sabe que ciertos aspectos del lenguaje no tienen pertinencia en la teoría lingüística. La respuesta de los estructuralistas se reduce a una serie de afirmaciones axiomáticas: no forman parte del quehacer lingüístico los datos que pertenecen a la sustancia, ni los que no tienen interpretación estructural; hay que separar lo variable de lo "constante", que constituye el foco de interés exclusivo de la lingüística estructural. La que se define así es una teoría del signo lingüístico; el cometido de los lingüistas es simplemente hallar la serie de propiedades menos compleja que defina el signo lingüístico. La exclusión de los hechos de sustancia se basa en la consideración de que el signo representa la unión constante de una forma del significante con una forma del significado; la constancia de la unión

${ }^{63}$ Son elocuentes las palabras de EMILIo Alarcos: "Aunque admiramos la rigurosa construcción mental de la llamada gramática generativa y transformativa $[\ldots]$, se ha de decir con toda sinceridad que [...] no añaden prácticamente nada nuevo a lo que ya sabíamos"', Estudios de gramática funcional..., p. 10 .

${ }^{64}$ Muchas veces, las razones de "simplicidad" se aducen indirectamente como "conveniencia" o de "lógica de la investigación". 
da cuenta de por qué se considera como puramente lingüístico sólo lo invariable, que subyace a las manifestaciones variables.

Dada la definición de una lengua como un sistema simbólico, o sea, un sistema de signos, el criterio de la simplicidad se pone de manifiesto de varias maneras. Se busca un sistema unitario, con pocas clases de signos, regidos por el menor número posible de principios estructurales. El carácter global de los estudios teóricos representativos no sólo se debe a falta de espacio y tiempo, sino también a un intento de restringir severamente los conceptos y definiciones primitivos, ampliando en lo posible las derivaciones que completen la teoría. Así, por ejemplo, André Martinet construye su teoría funcional sobre el concepto de monema, unidad primaria, derivando de él conceptos secundarios mediante una serie de deducciones que se suponen lógicamente necesarias o accesibles a la intuición. Emilio Alarcos se muestra más "liberal", pero construye toda su teoría de las categorías léxicas sobre la base del concepto primitivo de "signo independiente", definiendo los verbos como signos independientes por esencia, los nombres como signos dependientes de los verbos, aunque independientes por accidente, etc.

La teoría lingüística más "simple" es, por tanto, la que usa menos conceptos y definiciones primitivas. Este criterio de "simplicidad" puede mantenerse en el marco teórico estructural, ya que la lingüística se considera como la ciencia de los signos lingüísticos.

5.2.2. En la tradición generativa abundan las discusiones sobre el criterio de la "simplicidad"'65. Se considera que tiene pertinencia solamente si se comparan dos hipótesis descriptivamente adecuadas; o sea, sólo en el caso de que dos hipótesis describan de una manera eficaz los mismos datos tendrá sentido aplicar el criterio de la "simplicidad" 66 . Como esta situación casi nunca se

65 Ya se halla en Chomsky, The Logical Structure of Linguistic Theory, Plenum, New York, 1975 [1 ${ }^{\mathrm{a}}$ ed., 1955]. Véase también R. P. Bотна, The Function of the Lexicon in Transformational Generative Grammar, Mouton, The Hague, 1968.

${ }^{66} \mathrm{La}$ "medida de evaluación" (evaluation measure) ha sido estudiada con mayor detenimiento en N. Chомsкy y M. Halle, The Sound Pattern of English, Harper \& Row, New York, 1968, donde se aplica a la teoría fonológica. En M. HALLE, "Phonology in Generative Grammar", Word, 18 (1962), 54-72, encontramos una exposición particularmente convincente, así como otras relativas a la necesidad de usar rasgos fonológicos en vez de fonemas, como unidades fundamentales del análisis fonológico. 
presenta al investigador, el criterio ha tenido pocos efectos en la investigación ${ }^{67}$.

Hay, eso sí, un esfuerzo permanente y constante por reducir en lo posible el número de conceptos y definiciones primitivas, pero no se evitan inventarios bastante extensos. El criterio no se tiene en cuenta en el momento de construir hipótesis, sino después de formularlas ${ }^{68}$.

En los últimos años se nota otra interpretación del criterio, íntimamente ligada con uno de los cometidos fundamentales de la gramática generativa. Se trata de saber cómo el hablante ha adquirido los conocimientos que pone en práctica al hablar y entender su lengua materna. Los datos de que dispone son relativamente asistemáticos y defectuosos, de modo que el aprendizaje se realiza en circunstancias poco favorables.

La tarea de construir una gramática adecuada debe ser relativamente sencilla, ya que los datos no son suficientes para poder basar en ellos reglas complejas. El criterio de "simplicidad" que se introduce de esta manera no es criterio metodológico general, sino una hipótesis de trabajo relativa a la adquisición de las lenguas naturales. La hipótesis parece ser incompatible con la enorme complejidad de los datos lingüísticos. La aparente compatibilidad se resuelve suponiendo que la gramática se compone de una serie de "teorías" sumamente sencillas, cada una de las cuales explica una pequeña parte de los datos; así, por ejemplo, la "teoría" de los Casos explica la distribución de SN; la "teoría" X-barra explica la composición interna de los constituyentes; la "teoría" de la categoría vacía explica la distribución de la misma, etc. ${ }^{69}$ La complejidad de los datos se explica de dos mane-

${ }^{67}$ El llamado "generativismo semántico" se basó en consideraciones de "simplicidad", como se puede ver en G. Lakoff, Irregularity in Syntax, Holt, Rinehart \& Winston, New York, 1970; y J. D. McCawLEy, "Where Do Noun Phrases Come From"', en R. Jacobs y P. Rosenbaum (eds.), Readings in English Transformational Grammar. Los estudios de CHOMSKy, "Remarks on Nominalization", y de M. Brame, Conjectures and Refutations in Syntax and Semantics, Elsevier-North Holland, New York, 1976, mostraron las falacias del "generativismo semántico", que ya no se toma en consideración en los estudios generativos actuales.

${ }^{68} \mathrm{Al}$ respecto deben mencionarse los estudios de R. Freidin, "Cyclicity and the Theory of Grammar", LI, 9 (1978), 31-126; y J. Koster, Locality Principles in Syntax, Foris, Dordrecht, 1978.

${ }^{69}$ Véanse Chomsky, Lectures on Government...; Some Concepts and Consequences...; J. KOSTER, op. cit.; y las tesis doctorales citadas de BORER, Bouchard, JaEgGli, Marantz y Stowell, que ponen en práctica esta hipótesis fundamental. 
ras: en primer lugar, la interacción o la acción en conjunto de estas "teorías" hace que se conjuguen varios factores independientes en la interpretación o producción de los datos lingüísticos; en segundo lugar, aparte del sistema nuclear que se aprende fácilmente se adquiere un sistema periférico con estructura más compleja, definida mediante "teorías" periféricas de cierta complejidad.

Nótese que el estudio de las cláusulas relativas ha arrojado resultados muy "simples": la "teoría" de los Casos es pobre en reglas; la "teoría" de la anáfora se compone de un solo principio; la "teoría" de los pronombres anafóricos no ligados cuenta con un solo principio; etc. La complejidad de los datos se debe a que varias teorías se aplican al mismo tiempo, refiriendo a distintos aspectos de la construcción pertinente. La hipótesis generativa obedece, pues, al criterio de la "simplicidad" tal como se interpreta actualmente en la teoría generativa.

En resumidas cuentas, en los estudios generativos debemos distinguir entre el criterio metodológico de "simplicidad", según el cual de dos hipótesis empíricamente fundadas se debe escoger la más "simple", lo que supone un esfuerzo general de reducir el número de conceptos primitivos, y una hipótesis de trabajo reciente, basada en la cuestión del aprendizaje de las lenguas naturales, según la cual son "simples" las distintas "teorías" que explican aspectos determinados de los datos lingüísticos, teorías que deben ser adquiridas sobre la base de datos defectuosos y que, por ende, deben ser poco complejas.

5.2.3. La diferente interpretación que dan los estructuralistas y los generativistas al concepto de "simplicidad" se debe a dos circunstancias que conviene tener en cuenta. La primera es que el objeto de investigación del estructuralismo, el signo lingüístico, se considera homogéneo, por lo que su explicación se supone homogénea también, mientras que los generativistas no creen homogéneo su objeto de estudio, la gramática que ha adquirido el hablante de una lengua natural. El criterio de "simplicidad" tiene interpretación mucho más evidente en el estructuralismo, donde casi nunca se discute seriamente, que en el generativismo, que cuenta con una larga tradición de discrepancias explícitas al respecto. La segunda circunstancia es que la "simplicidad", criterio aceptado en todas las ciencias, constituye al mismo tiempo en el marco del generativismo una hipótesis de trabajo concerniente a las conclusiones que es lícito sacar de una teoría general del aprendizaje de las lenguas naturales. 


\subsection{La "función" en el estructuralismo y el generativismo}

5.3.0. El concepto de función se encuentra en los dos marcos teóricos que estamos comparando. La corriente estructural con la que se siente afín Emilio Alarcos se suele llamar funcionalismo o gramática funcional; la teoría generativa tiende a dedicar bastante atención a consideraciones funcionales. Nuevos modelos inspirados por el generativismo "ortodoxo", tales como Dik y Brame ${ }^{70}$, se declaran funcionales o subrayen la importancia del concepto de función. El uso del mismo término no delata una convergencia de distintos modelos; la función forma parte de teorías distintas, con distinta interpretación, como veremos en esta sección.

5.3.1. Los "estudios de gramática funcional" de Emilio Alarcos definen la orientación teórica del autor; André Martinet es autor de una "gramática funcional" del francés; otros lingüistas estructuralistas discuten el concepto de "función”, en la lingüística. ¿Qué se entiende en estos estudios por función? Nótese que la denominación no se define explícitamente; la presentación más clara se halla en el prefacio de Emilio Alarcos:

El enfoque que predomina en [los estudios que en este libro se recogen], estructural y funcional, ya no representa hoy en nuestro país ninguna novedad. Todos - y en todos los dominios científicosmanejamos ahora con habilidad - y hasta con frivolidad - esos dos adjetivos "estructural" y "funcional", y los correspondientes sustantivos "estructura" y "función". Cualquiera podrá ver que en estos estudios se adoptan puntos de vista procedentes de tres grandes maestros: Hjelmslev, Jakobson y Martinet, ... ${ }^{71}$

Del contenido de los estudios que acompañan a este prefacio podemos deducir que lo funcional reside en la preocupación por la función que cumple el signo en el discurso. Dada la polisemia del concepto de función, esto no aclara cómo se debe definir la orientación. Por ejemplo, se puede sostener que la función del uso de los pronombres es la abreviación de lo consabido, con lo que función viene a ser algo como causa; podemos decir también que

${ }^{70}$ S. C. DiK, Functional Grammar, North-Holland, Amsterdam, 1978; Studies in Functional Grammar, Academic Press, London, 1980; M. Brame, Essays Toward Realistic Sintax, Amrofer, Seattle, 1979.

71 Alarcos, op. cit. 
los constituyentes que se hallan en primera posición tienen la función, o sea, la tarea de definir el "tema" del enunciado. Lo funcional que orienta los estudios de Alarcos y Martinet debe entenderse de una manera más específica, ya que se asocia con lo estructural. Si por estudio estructural lingüístico entendemos el estudio del signo lingüístico, estudio funcional debe entenderse como el estudio de las funciones que cumplen los signos. La función de un signo ha de entenderse como las relaciones que contrae con otros signos, con lo que se define, en realidad, el cometido de la sintaxis en sentido tradicional. Esta interpretación limita se justifica debido a que el estructuralismo no funcional se distingue precisamente por el descuido de la sintaxis. Los estudios de Bernard Pottier, por ejemplo, no tratan la sintaxis propiamente dicha (aunque no faltan algunas observaciones dispersas al respecto), sino que se limitan a presentar una investigación de la morfosintaxis. El funcionalismo estructural ha de entenderse, pues, como una simple etiqueta para designar a la investigación estructural de tipo sintáctico.

A este sentido estricto se añade otro más amplio; se trata de una "orientación funcional", que sobrepasa los límites de la sintaxis propiamente dicha. En esta orientación funcional se incluyen aspectos estilísticos y textuales, así como pragmáticos y sociolingüísticos. En resumidas cuentas, el funcionalismo estructural comprende el estudio de la sintaxis del signo lingüístico, orientándose también hacia la investigación de las "funciones" - o valores- estilísticas, textuales, y recientemente, pragmáticas y sociolingüísticas.

5.3.2. El funcionalismo que se trata en gramática generativa se manifiesta como una orientación especulativa sobre los fenómenos lingǘsticos. Se puede rastrear en una serie de exposiciones relativas a la razón de ser del modelo explicativo, o de sus aspectos más peculiares. Por ejemplo, dada la equivalencia de las estructuras activas transitivas y las pasivas, se proponía una regla de pasivización que convertía las estructuras activas en las pasivas correspondientes. La "regla de pasivización" se caracterizaba como una sola operación, consistente en que el complemento directo de la estructura activa se convertía en el sujeto de la pasiva, al mismo tiempo que se insertaba el verbo auxiliar ser construido con el participio pasado del verbo principal. La especulación funcional consistía en intentar descubrir cómo se podía explicar que estas tres operaciones se dieran juntas. La respuesta tentativa ha sido que el verbo principal se convierte en adjetivo por la 
terminación del participio pasado; los adjetivos no admiten SN léxico en posición de complemento, puesto que no le asignan marca de Caso; si el verbo transitivo requiere complemento directo, éste ha de convertirse en sujeto, adquiriendo marca de Caso de INFL, constituyente que no puede asociarse con el verbo en participio pasado, sino que requiere el uso del verbo finito ser. Una explicación de este tipo puede ser caracterizada como funcional, ya que los cambios se definen en función de un solo cambio fundamental.

Nótese que en los estudios "funcionales"' ni siquiera se usa mucho este término, que se reduce a un intento de establecer una cadena de causa y efecto; el efecto puede ser descrito como función, en sentido matemático, de la causa ${ }^{72}$.

En un sentido semejante, se puede sostener que ciertas restricciones relativas a la "localidad" de los fenómenos lingüísticos ${ }^{73}$ tienen función psicológica, ya que la mente humana sólo puede realizar operaciones locales. Las restricciones tales como la Adyacencia, la Subyacencia y otras que no han sido tratadas en este estudio se interpretan, pues, en función de la estructura de la mente humana.

Se usa otro sentido más técnico cuando se dice que los constituyentes cuya "función" en el enunciado o discurso ha quedado sin definir producen la agramaticalidad del enunciado. Muchas veces, se trata de la función gramatical en sentido tradicional, o la función temática que se establece actualmente ${ }^{74}$.

Nótese que no se distingue una corriente funcional en el generativismo, sino que se trata de la mayor o menor atención a ciertos aspectos metodológicos denominados funcionales. El funcionalismo ocupa los estudios actuales de gramática generativa, entendiéndose por esto que se intenta hallar la "función' de ciertos aspectos de la teoría en otros. O sea, la estructura de las distintas "teorías" que se proponen y su interacción se estudia teniendo

72 Pueden considerarse fundamentales las obras de J. R. Ross, Constraints on Variables in Syntax, tesis doctoral, Massachusetts Institute of Technology, Cambridge, 1967 y de J. E. Emonds, A Transformational Approach to English Syntax: Root, Structure-Preserving and Local Transformations, Academic Press, New York, 1976, en que ni siquiera se usa la palabra "funcional". En la línea de estos trabajos se halla el estudio de las "condiciones sobre las reglas" iniciado en CHомsкy, "Remarks on Nominalization"; véase también "On- WHMovement".

${ }^{73}$ Véanse J. Koster, op. cit.; T. StOWell, op. cit.

${ }^{74}$ Véanse A. Rouveret y J. R. Vergnaud, "Specifying Reference to the Subject"', LI, 11 (1980), 97-203; y CHOMSKy, Lectures on Government... 
en cuenta sus efectos en las demás “teorías" y en la interpretación global del enunciado.

5.3.3. Concluimos que el auge del enfoque funcional en el estructuralismo y el generativismo no se debe a una convergencia de las dos teorías, sino que se trata de dos desarrollos independientes que no comparten más que la etiqueta. El estructuralismo funcional define una corriente orientada hacia el estudio de los fenómenos sintácticos, mientras que el generativismo funcional define una preocupación creciente por ciertos aspectos metodológicos, sin que se trate de una nueva orientación.

\subsection{Resumen y conclusión}

En el estudio de las cláusulas relativas en español revisten cierto interés dos fenómenos que se han designado como la adjetivación de las cláusulas relativas y la distribución de los pronombres relativos. Se nota que los dos temas pueden y deben ser tratados, tanto en el marco de la teoría estructural como en el marco de la teoría generativa. No cabe duda que las maneras específicas de explicar los temas pueden adaptarse en los dos marcos teóricos, o sea, las "teorías"' que se han propuesto en una teoría pueden ser adaptadas a la otra. El valor del método estructural o el generativo no puede ser determinado teniendo en cuenta, las "teorías" que se han propuesto para dar cuenta de estos dos temas de investigación, puesto que éstas podrían haber sido adoptadas también en el otro marco teórico. Observamos, eso sí, una diferente apreciación de la importancia que tienen los dos temas de investigación. La adjetivación de las cláusulas relativas ha constituido el campo de estudio predilecto de los estructuralistas, mientras que los generativistas se han mostrado preocupados por la distribución de los pronombres relativos. Esto se debe a los distintos objetivos que persiguen. Si se interpreta la investigación lingüística como el estudio del signo lingüístico, se define el objeto de investigación de los estructuralistas. Los generativistas, en cambio, consideran que la gramática de las lenguas naturales que han sabido construir los hablantes es su objeto de investigación.

Debido a la diferente orientación de estructuralistas y generativistas, no sólo se comprende la apreciación distinta de temas de 
investigación determinados, sino también las discrepancias relativas al uso de conceptos aparentemente semejantes, tales como el de "simplicidad" y el de "función".

Reijksuniversiteit, Utrecht

\section{Jan SCHROTEN}

